ISSN: 0213-2060

DOI: https://doi.org/10.14201/shhme2020382155187

\title{
EL POBLAMIENTO EN EL INTERIOR DE LA GALLAECIA ENTRE EL FINAL DEL IMPERIO ROMANO Y LA ALTA EDAD MEDIA: NUEVOS DATOS, NUEVAS PROPUESTAS ${ }^{1}$
}

\author{
Settlement Patterns in Inland Gallaecia between the End of the Roman Empire and the \\ Early Middle Ages: New Data, New Proposals
}

\author{
Carlos TEJERIZO GARCÍA \\ Depto. de Geografia, Prehistoria y Arqueología. Facultad de Letras. Campus de Álava. Universidad del Pais Vascol \\ Euskal Herriko Unibertsitatea. C/ Tomás y Valiente, s/n. E-01006 VITORIA-GASTEIZ. C. e.: carlosteje@gmail.com
}

Recibido: 2020-02-11

Revisado: 2020-06-04

Aceptado: 2020-10-26

RESUMEN: Tradicionalmente, el noroeste peninsular en época altomedieval se había presentado en términos de excepcionalidad, como un territorio con características particulares y diferenciadas del resto de la Península Ibérica. Esta presunción generó algunos problemas en el análisis de la transformación del sistema de poblamiento entre el fin del Imperio Romano y la Alta Edad Media. La incorporación de nuevos registros, sobre todo aquellos provenientes de la arqueología comercial y de algunos proyectos de investigación específicos, están permitiendo no solo reconocer algunos importantes fenómenos, en términos de poblamiento, similares a otros territorios peninsulares, como la emergencia de la aldea altomedieval, sino también reconsiderar otros, como el papel de los asentamientos fortificados en altura. En este trabajo se presentan algunas reflexiones e hipótesis sobre la transformación del poblamiento en el interior de Gallaecia en este período a partir de los nuevos datos arqueológicos disponibles.

Palabras clave: Poblamiento; Noroeste peninsular; Arqueología; Aldeas; Alta Edad Media.

1 Este trabajo ha sido realizado en el marco del Proyecto «Agencia campesina y complejidad sociopolítica en el noroeste de la Península Ibérica en época medieval» (Ministerio de Economía, Industria y Competitividad, AEI/FEDER UE HUM2016-76094-C4-2-R), del Grupo de Investigación en Arqueología Medieval, Patrimonialización y Paisajes Culturales / ErdiArokoArkeologia, Ondaregintza eta KulturPaisaiakIkerketaT aldea(Gobierno Vasco, IT1193-19) y del Grupo de Estudios Rurales (Unidad Asociada UPV/EHU-CSIC). Agradezco a Celtia Rodríguez, Eduardo Daflon, Mario Fernández y Francisco Alonso los comentarios al texto. A José Fernández y a Santiago Ferrer, toda la ayuda para abordar la compleja arqueología de la comarca de Valdeorras. A los evaluadores la atenta lectura del texto y las aportaciones recibidas; cualquier error es obra exclusiva del autor. 
ABSTRACT: Traditionally, northwestern Spain during Early Middle Ages was presented in terms of exceptionality, as a territory with a set of particular characteristics which differentiated it from the rest of the Iberian Peninsula. This presumption created some problems dealing with the analysis of the transformation of the settlement pattern between the end of the Roman Empire and the Early Middle Ages. The introduction of new records, particularly those coming from Commercial Archaeology and some recent research projects, allows not only for recognizing some important phenomena regarding the settlement pattern in comparison with other peninsular territories, such as the emergence of the early medieval village, but also reconsidering others, such as the role of the fortified settlements. In this paper some reflections and hypothesis on the transformation of the settlement pattern in the inner territory of Gallaecia during this period through the new available archaeological data are presented.

Keywords: Settlement pattern; Northwestern Iberia; Archaeology; Villages; Early Middle Ages.

SUMARIO: 0 Introducción: Gallaecia, entre la normalidad y la excepcionalidad. 1 Apuntes historiográficos sobre el análisis del poblamiento entre el mundo romano y la Alta Edad Media. 2 Entre villas, vicus y castros. El sistema de poblamiento durante el Tardoimperio. 2.1 Los efectos de la implantación del Imperio Romano en el noroeste. 2.2 La transformación del sistema de poblamiento tardoimperial. 3 ¿ Granjas y aldeas en el noroeste? Nuevos datos sobre el mundo rural en la Alta Edad Media. 3.1 Granjas y aldeas en el interior de la Gallaecia: algunos apuntes. 3.2 La estructuración social del paisaje altomedieval. $4 \mathrm{El}$ sistema de poblamiento en el interior de la Gallaecia: algunas consideraciones generales. 5 Conclusiones. 6 Referencias bibliográficas.

\section{INTRODUCCIÓN: GALLAECIA, ENTRE LA NORMALIDAD Y LA EXCEPCIONALIDAD}

La celebración del congreso O Priscilianismo e Gallaecia en Santiago de Compostela en septiembre de 2018 puso de relieve varias cuestiones de relevancia ${ }^{2}$. En primer lugar, la existencia de una larga tradición de estudios en el noroeste sobre un período, aquel correspondiente a los momentos finales del Imperio Romano y el inicio de la Alta Edad Media $^{3}$, que hasta muy recientemente había sido olvidado ${ }^{4}$.

2 Toda la información relacionada con este encuentro puede localizarse en: http://consellodacultura. gal/evento.php?id=200731 [consultado el 23 de septiembre de 2019].

3 A lo largo del texto se utilizará el término "Tardoimperio" para referirse a estos momentos finales de la administración imperial en la Península Ibérica, que abarca, grosso modo, el siglo iv y la primera mitad del siglo v, y el término "Alta Edad Media» para referirse a los momentos posteriores a este momento, siguiendo las propuestas de la reciente historiografía francesa: Nissen-Jaubert, Anne. «Le haut Moyen Âge». En Ferdière, Alain; Malrain, François; Matterne, Véronique; Méniel, Patrice y Nissen-Jaubert, Anne (eds.). Histoire de l'agriculture en Gaule. Paris: Éditions Errance, 2006, pp. 141-197.

4 Díaz Martínez, Pablo de la Cruz. El Reino Suevo (411-585). Tres Cantos: Akal, 2011; Sánchez PArdo, José Carlos. «Poblamiento rural tardorromano y altomedieval en Galicia (ss. v-X). Una revisión arqueológica». Archeologia Medievale, 2010, vol. XXXVII, pp. 285-306. 
En segundo lugar, la puesta de relieve de una serie de particularidades que caracterizaron a la antigua provincia de Gallaecia durante ese período. Entre estas particularidades, en el encuentro se subrayaron sobre todo dos. Por un lado, que este territorio fue escenario de la emergencia de uno de los primeros reinos post-romanos, el reino Suevo, que, en su momento de máxima expansión, desbordó los límites políticos y administrativos de la antigua provincia romana. Otra particularidad de este territorio, y el tema central del encuentro, sería la emergencia del Priscilianismo, fenómeno que mostraría unas específicas dinámicas sociales y religiosas en el noroeste peninsular. Ambas particularidades, entre otras, han generado que, de forma recurrente en la historiografía, se hable de la Gallaecia entre el Imperio Romano y la Alta Edad Media en términos de excepcionalidad.

En tercer y último lugar, y tomando en cuenta el programa específico de las contribuciones al congreso, la relevancia que el registro arqueológico ha adquirido en el análisis del sistema de poblamiento del territorio entre los siglos $\mathrm{v}$ y x d.n.e. Así, de un total de 26 contribuciones al encuentro, 16 de ellas (un 61\%) tenían que ver directamente con este tema. Sin duda, como advierten diversos investigadores, vivimos un momento en el que la cuestión de la transición entre el mundo romano y la Edad Media en el territorio de Gallaecia es un tema de gran interés científicos.

Sin embargo, y a pesar del auge de las excavaciones, investigaciones y publicaciones en torno a la arqueología de este período, aún son escasas las contribuciones que han tratado de abordar el sistema de poblamiento en su conjunto desde una perspectiva diacrónica y comparada con otros territorios peninsulares. Esto se debe, en mi opinión, a dos razones principales. En primer lugar, a la todavía incipiente incorporación en el noroeste peninsular de los datos provenientes de la arqueología comercial, en comparación con otros territorios donde esta ha permitido una renovación de los estudios sobre el sistema de poblamiento entre el fin del Imperio Romano y la Alta Edad Media ${ }^{6}$. En segundo lugar, a la permanencia de ciertos paradigmas historiográficos que generan algunos apriorismos a la hora de abordar este registro arqueológico. Así, el objetivo principal de este trabajo es ofrecer algunas reflexiones historiográficas y analíticas sobre las transformaciones del sistema de poblamiento entre el fin del Imperio Romano y la Alta Edad Media que, fundamentadas en datos arqueológicos provenientes tanto del ámbito de la arqueología comercial como de un proyecto de investigación en marcha, permitan profundizar en sus particularidades y similitudes con otros territorios durante este período así como de las potencialidades y límites en el contexto del noroeste peninsular. En este trabajo se abordarán dos temas principales: por un lado, la desarticulación del Imperio Romano

5 SÁNChez PARDo, José Carlos. «Power and rural landscapes in early medieval Galicia (400-900 AD): towards a re-incorporation of the archaeology into the historical narrative». Early Medieval Europe, 2013, vol. 21, n.o 2, pp. 140-168; Fernández Pereiro, Mario. Recintos fortificados en altura na costa atlátinca galega. Estudo arqueolóxico. Tesis inédita. Santiago de Compostela: Universidad de Santiago de Compostela, 2018; Fernández Fernández, Adolfo. El comercio tardoantiguo (ss. IV-VII) en el Noroeste peninsular a través del registro cerámico de la ría de Vigo. Oxford: Archaeopress, 2014.

6 Quirós Castillo, Juan Antonio. «Medieval Archaeology in Spain». En Gilchrist, Roberta y ReyNOLDs, Andrew (eds.). 50 years of medieval archaeology in Britain and beyond. London: Routledge, 2009, pp. 173-189. 
y su impacto en el sistema de poblamiento; $y$, por otro, la emergencia de nuevas formas de poblamiento rural a partir de la sexta centuria. Para ello, tomaremos como contexto geográfico de estudio el interior oriental de la antigua provincia de Gallaecia, un territorio que, debido a la incorporación de nuevos datos en los últimos ańos, permite analizar con un cierto grado de profundidad las transformaciones en el sistema de poblamiento. En última instancia, lo que se tratará de ofrecer son algunos apuntes críticos sobre este tema fundamentados en los datos arqueológicos, de tal manera que sirvan como fundamento para futuros debates y trabajos.

\section{Apuntes historiográficos sobre el ANÁlisis Del poblamiento ENTRE EL mundo romano y la Alta Edad Media}

Las formas en las que las sociedades altomedievales han organizado su poblamiento ha sido un aspecto repetidamente abordado por los especialistas debido a su capacidad para profundizar en aspectos como el sistema económico, la estructuración social o las desigualdades sociales ${ }^{7}$. Más aún, la arqueología ha sido una herramienta fundamental a la hora de construir narrativas históricas de las sociedades de este período tomando como base el sistema de poblamiento ${ }^{8}$. Sin embargo, desde el punto de vista historiográfico, a la hora de afrontar esta cuestión, el noroeste peninsular se ha constituido como una excepción paradójica. Así, si bien existe una larga tradición que ha generado una voluminosa cantidad de estudios dedicados a este tema, estos se han visto comúnmente limitados por una parca evidencia empírica, muchas veces abordada de forma poco crítica?

En parte, esta diversidad de narrativas se explica por su constitución como un «agujero negro» en la historiografía del noroeste. El particular proceso de institucionalización académica de la Historia en Galicia ${ }^{10}$ ha ocasionado que el período entre el Imperio Romano y la Alta Edad Media haya sido abordado, simultáneamente, por prehistoriadores, romanistas y medievalistas, cada uno impregnando estos debates desde metodologías y

Martín VIso, Ińaki. Asentamientos y paisajes rurales en el occidente medieval. Madrid: Editorial Síntesis, 2016.

8 Quirós Castillo, Juan Antonio (ed.). Social complexity in Early Medieval Rural Communities. The north-western Iberia Archaeological Record. Oxford: Archaeopress, 2016; Tejerizo García, Carlos. «Settlement patterns and social inequality: The Duero Basin in Early Middle Ages (4th-8th centuries)». En QurRós Castillo (ed.), Social complexity in Early Medieval Rural Communities, pp. 17-34; Fernández Mier, Margarita. Génesis del territorio en la Edad Media: arqueología del paisaje y evolución histórica en la montaña asturiana. Oviedo: Universidad de Oviedo, 1999.

9 SÁnchez PARdo, «Poblamiento rural».

10 Tejerizo García, Carlos y Quirós Castillo, Juan Antonio. «Treinta años de arqueología en el norte de la Península Ibérica. La 'otra' Arqueología Medieval». En Quirós Castillo, Juan Antonio (ed.). Treinta años de Arqueología Medieval en España. Oxford: Archaeopress, 2018, pp. 123-146; GonzÁlez RuIBaL, Alfredo. Galaicos. Poder y comunidad en el Noroeste de la Peninsula Ibérica (1200 a. C-50 d. C). A Coruña: Museo Arqueolóxico e Histórico de A Coruña, 2006-2007; Vigil-Escalera Guirado, Alfonso. «Los últimos 30 años de la arqueología de época visigoda y altomedieval». En Quirós Castillo (ed.), Treinta años de Arqueología Medieval en España, pp. 271-294. 
posiciones específicas ${ }^{11}$, beneficiando algunos aspectos y relativizando otros. A esto se suma una peculiar forma de instrumentalización, no exento de unas connotaciones políticas muy específicas vinculadas con -o en contra- el nacionalismo gallego a partir del siglo XIX, tal y como han seńalado autores como P. C. Díaz ${ }^{12}$. Abordar estas cuestiones desde un punto de vista historiográfico y crítico es crucial para entender el punto de partida del análisis que aquí se presenta.

A modo de síntesis se pueden distinguir cuatro tendencias historiográficas generales en el análisis e interpretación del sistema de poblamiento en este momento histórico. En primer lugar, se presentaría aquella que, desde un punto de vista que parte de la Prehistoria Reciente -la denominada cultura castreña en el contexto del noroeste peninsular-, presentaría un sistema del poblamiento centrado en el castro como topos arqueológico para comprender la evolución del poblamiento posterior a la implantación del Estado romano. Una mirada normalmente vinculada al trabajo de los prehistoriadores ${ }^{13}$, aunque no de forma exclusiva ${ }^{14}$. De esta manera, el poblamiento en el noroeste, prácticamente hasta bien entrada la Edad Media, estaría articulado fundamentalmente a partir de la ocupación de los castros, eje central de un poblamiento castrexo que simbolizaría la continuidad de las relaciones sociales, las identidades étnicas y/o las demarcaciones territoriales existentes antes de la conquista romana ${ }^{15}$. En general, estos estudios han tendido a relativizar o minimizar el impacto del Imperio Romano al mismo tiempo que han subrayado los aspectos de continuidad con respecto a las sociedades de la Edad del Hierro, tanto en lo social como en lo político ${ }^{16}$.

En segundo lugar, se situarían aquellas interpretaciones para las que el impacto del Imperio Romano fue tan significativo en el noroeste como en el resto de la Península Ibérica ${ }^{17}$. De esta manera, el sistema de poblamiento de la Edad del Hierro entraría en un

11 Rodríguez Sánchez, Brais. «O proceso de abandono dos castros. 'Continuidades' e 'rupturas' entre a Idade do Ferro e a Alta Idade Media. Un estado da cuestión». Gallaecia, 2012, vol. 31, pp. 139-151.

12 Díaz Martínez, El Reino Suevo.

13 Ayán Vila, Xurxo. Casa, familia y comunidad en la Edad del Hierro del NW. Santiago de Compostela: Xurimaru Servizos de Comunicación, 2012.

14 Martín Viso, Ińaki. Poblamiento y estructuras sociales en el norte de la Península Ibérica (siglos VI-XIII). Salamanca: Ediciones Universidad de Salamanca, 2000; DíAz Martínez, Pablo de la Cruz. "El alcance de la ocupación sueva de Gallaecia y el problema de la germanización». En Galicia: da romanidade á xermanización: problemas históricos e culturais: actas do encontro cientifico en homenaxe a Fermín Bouza Brey (19011973). Santiago de Compostela: Museo do Pobo Galego, 1993, pp. 209-226.

15 Criado Bondo, Felipe. Arqueología del paisaje. El área Bocelo-Furelos entre los tiempos paleolíticos y medievales. A Coruña: Xunta de Galicia, 1992; Arizaga Castro, Álvaro R. y Ayán Vila, Xurxo M. «Etnoarqueología del paisaje castreño. La segunda vida de los castros». En González García, Francisco Javier (ed.). Los pueblos de la Galicia Céltica. Madrid: Akal, 2007, pp. 445-531; RodríGuez Fernández, Tomás. «El fin del mundo fortificado y la aparición de las 'aldeas abiertas'. La evidencia del centro-oriente de Lugo (Samos y Sarria)». Espacio, Tiempo y Forma. Serie I, Prehistoria y Arqueología, 1994, vol. 7, pp. 153-189; PARCEro OuBIÑA, César. "Tres para dos. Las formas de poblamiento en la Edad del Hierro del Noroeste Ibérico». Trabajos de Prehistoria, 2000, vol. 57, n. ${ }^{\circ} 1$, pp. 75-95.

16 Rodríguez Sánchez, Brais. «O proceso de abandono dos castros».

17 Carlsson-Brandt Fontán, Erik. «El poblamiento rural romano en Galicia. Resultados preliminares». Férvedes, 2011, vol. 7, pp. 207-213; PÉrez Losada, Fermín. Entre a cidade e a aldea. Estudio arqueohistórico dos 'aglomerados secundarios' romanos en Galicia. A Coruña: Museo Arqueolóxico de A Coruña, 2002; 
punto de no retorno en el cambio de era, lo que no descartaba el mantenimiento de ciertas formas específicas de articulación del poblamiento provenientes del período anterior, caso por ejemplo de la continuada ocupación de algunos castros tras la conquista roma$\mathrm{na}^{18}$. Algunas propuestas que parten de esta idea de transformación sustancial del patrón de poblamiento subrayarían el papel de las corrientes priscilianistas y fructuosianas a la hora de articular el poblamiento desde fechas tan tempranas como el siglo $\mathrm{v}$ d.n.e. ${ }^{19}$, realzando con ello los aspectos culturales, religiosos e identitarios como elementos vertebradores de la sociedad en general y del poblamiento en particular.

En tercer lugar, se podrían diferenciar aquellos estudios que, desde la medievalística, entenderían el poblamiento entre los siglos v y viII como el origen de lo que serían posteriormente las villas medievales, de tal manera que la ruptura en el sistema de poblamiento se situaría en torno a la octava centuria, o incluso más tarde ${ }^{20}$. Particularmente, sería el proceso de creación de las parroquias el que centraría la articulación del poblamiento en época medieval ${ }^{21}$. Desde este punto de vista, el sistema de poblamiento anterior a la implantación de la villa medieval se caracterizaría como disperso, desarticulado o marginal $^{22}$. Igualmente, la cuestión de la emergencia de estas villas se presentaría como un antecedente más o menos directo del actual sistema de poblamiento presente en Galicia.

Cada una de estas tendencias ha aportado una estimulante diversidad de narrativas que ha permitido resaltar diferentes aspectos sobre la cuestión del sistema de poblamiento en el período post-romano en el contexto del noroeste peninsular. Sin embargo, al mismo tiempo, cada una relativiza en alguna medida las particularidades del período. En este sentido, una cuarta línea historiográfica, revitalizada en los últimos años, ha subrayado el impacto que tuvieron las conocidas como «invasiones bárbaras» en el entramado poblacional del Tardoimperio como una especificidad del período ${ }^{23}$. Sin duda, estas aportaciones dotaron de un particularismo a este momento histórico que ha sido muy beneficioso a la hora de analizarlo en sí mismo, sin dependencias ni miradas hacia

Tranoy, Alain. La Galice Romaine. Recherches sur le nord-ouest de la Péninsule Ibérique dans l'Antiquité. Paris: Publications du Centre Pierre Paris, 1981.

18 Arias Vilas, Felipe. «Poblamiento rural: la fase tardía de la cultura castreña». En Fernández Оснон, Carmen (ed.). Los finisterres atlánticos en la Antigüedad: época prerromana y romana. Gijón: Electa, 1996, pp. 181-188; López Quiroga, Jorge y Lovelle, Mónica R. "Castros y castella tutiora de época sueva en Galicia y norte de Portugal: ensayo de inventario y primeras propuestas interpretativas». Hispania Antiqua, 1999, vol. XXIII, pp. 355-374.

19 LÓPEZ QUiRoga, Jorge. El final de la antigüedad en la Gallaecia: la transformación de las estructuras de poblamiento entre Miño y Duero (siglos V al X). La Coruña: Fundación Pedro Barrié de la Maza, 2004; RoDRÍGUEZ FERNÁNDEZ, «El fin del mundo fortificado».

20 Pallares Méndez, María del Carmen y Portela Silva, Ermelindo. «La villa por dentro: testimonios galaicos de los siglos x y xI». Studia Historica. Historia Medieval, 1998, vol. 16, pp. 13-43.

21 López Alsina, Fernando. «Da protoparroquia ou parroquia antiga altomedieval á parroquia clásica en Galicia». En García Pazos, Fernando (ed.). A parroquia en Galicia: pasado, presente e futuro. Santiago de Compostela: Xunta de Galiza, 2009, pp. 57-75.

22 García de Cortázar, José Ângel. «La formación de la sociedad feudal en el cuadrante noroccidental de la Península Ibérica en los siglos 8 a 12». Initium: Revista Catalana d'Historia del Dret, 1999, vol. 4, pp. 57-121.

23 Torres, Casimiro. Galicia sueva. A Coruña: Fundación Pedro Barrié de la Maza, 1977; Díaz Martínez, El Reino Suevo. 
lo anterior o lo posterior, sino otorgándole unas problemáticas particulares y un contexto histórico en el que cobraban su sentido ${ }^{24}$.

Es importante destacar en este brevísimo recuento historiográfico que estos enfoques no son excluyentes entre sí, sino que han sido combinados de diversas formas, pero cuyos planteamientos básicos pueden ser reconocidos y diferenciados. En la última década, en un contexto de renovación general de la historiografía altomedieval de la Península Ibérica, sobre todo en lo que tiene que ver con las cuestiones del mundo rural y del poblamiento ${ }^{25}$, las cuatro tendencias historiográficas anteriormente descritas han iniciado un estimulante diálogo que está dando lugar a formas renovadas de aproximación al poblamiento en la transición entre el Imperio Romano y la Alta Edad Media ${ }^{26}$. En este proceso de renovación historiográfica la arqueología está jugando un papel fundamental a la hora de proporcionar la evidencia empírica necesaria. En palabras de P. C. Díaz, y refiriéndose al reino suevo: «aún así, y ante el agotamiento de las fuentes escritas, es en la arqueología donde debemos situar nuestras esperanzas y expectativas de un futuro progreso en la investigación ${ }^{27}$.

Sin embargo, y a pesar de que la arqueología ya está efectivamente jugando ese papel renovador en el contexto del noroeste peninsular gracias a diversos proyectos de investigación específicos sobre el período que están incorporando nuevas metodologías y nuevos enfoques ${ }^{28}$, su potencial todavía está por desarrollar ${ }^{29}$. Esto se debe a dos cuestiones complementarias. Por un lado, la parcial integración de la ingente cantidad de datos provenientes del ámbito de la arqueología comercial, a pesar de que su impacto cuantitativo -que no cualitativo, como luego veremos- en la Comunidad Autónoma de Galicia ha sido similar a otras comunidades como Castilla y León o el País Vasco ${ }^{30}$. Por otro, esta situación se ha producido sustancialmente por la conjunción de algunos factores de estancamiento, como son, por ejemplo, la persistencia de algunos de los paradigmas anteriormente mencionados que generan una suerte de apriorismos que determinan la lectura de estos datos arqueológicos, o la falta de una crítica de base sobre esta masa de datos

24 SÁnchez PARdo, «Poblamiento rural»; SÁnchez Pardo, José Carlos. «Castros y aldeas galaicorromanas: sobre la evolución y transformación del poblamiento indígena en la Galicia romana». Zephyrus, 2010, vol. LXV, pp. 129-148.

25 Martín Viso, Asentamientos y paisajes rurales; Escalona Monge, Julio. "The early Castilian peasantry: an archaeological turn?». Journal of Medieval Iberian Studies, 2009, vol. 1, n. ${ }^{\circ}$ 2, pp. 119-145.

26 Portass, Robert. The village world of early medieval northern Spain. Local community and the land market. London: The Royal Historical Society, 2017; Sánchez Pardo, José Carlos. «Power strategies in the early medieval churches of Galicia (711-910 AD)». En Sánchez Pardo, José Carlos y Shapland, Michael G. (eds.). Churches and social power in Early Medieval Europe. Integrating Archaeological and Historical Approaches. Turnhout: Brepols, 2015, pp. 227-268.

27 Díaz Martínez, El Reino Suevo.

28 López Costas, Olalla y Muldner, Gundula. "Fringes of the empire: diet and cultural change at the Roman to post-Roman transition in NW Iberia». American Journal of Physical Anthropology, 2016 , vol. 161, pp. 141-154; Fernández Fernández, El comercio tardoantiguo; SÁnchez Pardo, "Power strategies».

29 Sánchez Pardo, «Power and rural landscapes».

30 Criado Boado, Felipe; Martínez López, María del Carmen y Amado Reino, Xesús. La arqueología en la gasificación de Galicia 1: programa de control y corrección de impacto arqueológico. Santiago de Compostela: Universidade de Santiago de Compostela, 1998. 
en cuestiones como la estratigrafía, la secuenciación o la cronología de los yacimientos ${ }^{31}$. Sin embargo, una lectura crítica y atenta de los datos arqueológicos permiten plantear $-\mathrm{o}$, mejor dicho, replantear- algunas importantes cuestiones sobre las transformaciones del poblamiento entre el Imperio Romano y la Alta Edad Media.

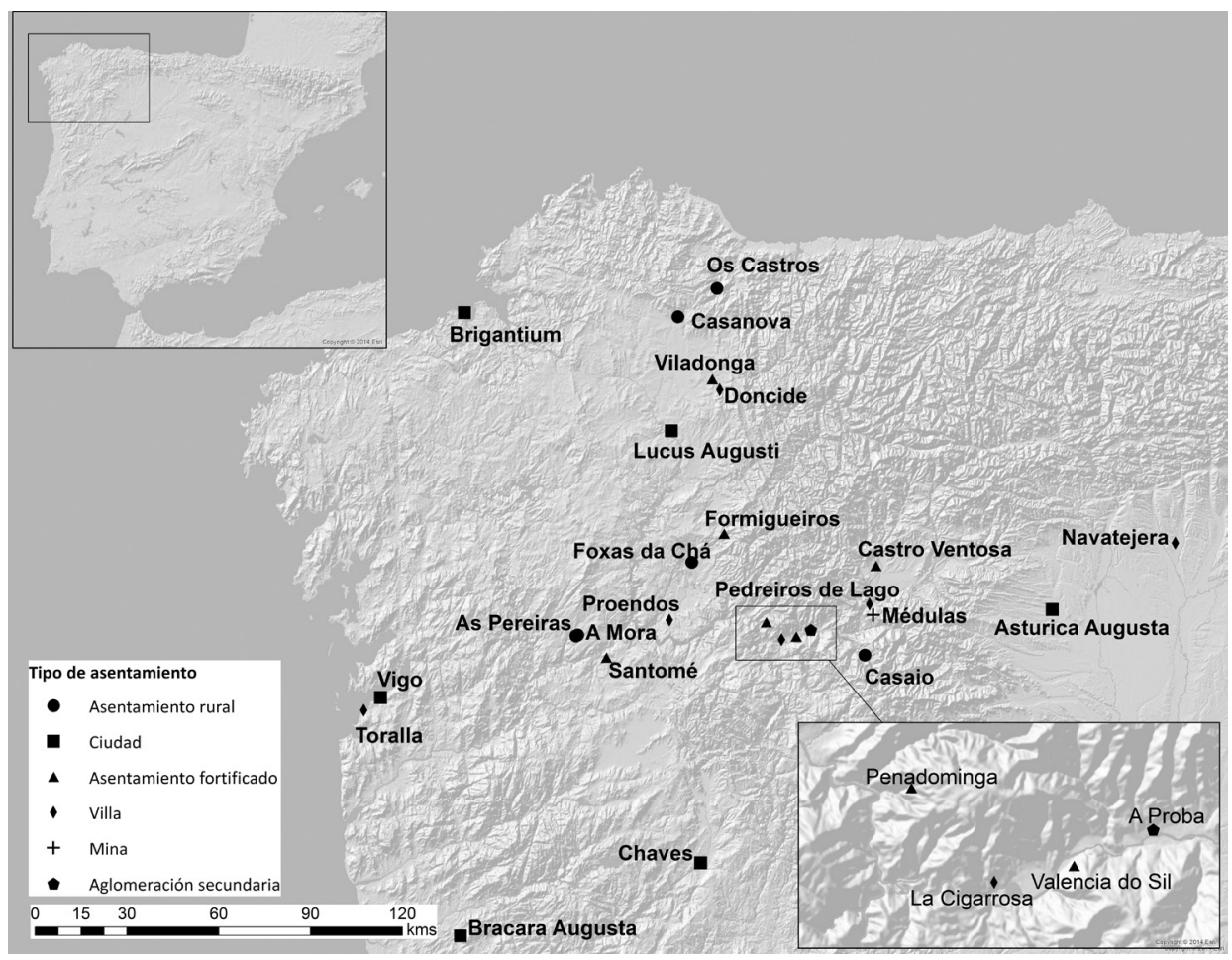

Figura 1. Yacimientos mencionados en el texto. Fuente: Elaboración propia.

2 Entre villas, Vicus y castros. El sistema de poblamiento durante el TARDOIMPERIO

\subsection{Los efectos de la implantación del Imperio Romano en el noroeste}

Como vimos en la sección anterior, el grado de implantación del Imperio Romano en el territorio de Gallaecia ha sido desigualmente visto por los especialistas. Si bien es

31 Fernández Pereiro, Mario; Tejerizo García, Carlos; Rodríguez González, Celtia; Lixó Gómez, Carlos y Carvajal Castro, Álvaro. «Asentamentos fortificados no interior da Gallaecia en época tardoimperial e sueva (séc. IV-vI): un achegamento a partir de varios casos de estudo». Gallaecia, 2017, vol. 36, pp. 129-162. 
cierto que, por un lado, todavía existe una carencia empírica para medir en términos generales cómo de integrado estuvo este territorio dentro de las dinámicas del Imperio ${ }^{32}$ $y$, por otro, que esta integración pudo variar de forma muy significativa dentro de la provincia -sobre todo entre la costa y el interior ${ }^{33}$. Teniendo en cuenta esto, se puede afirmar que, en términos generales, la integración de este territorio dentro de las dinámicas imperiales fue, al menos, tan completa como en otros espacios del norte peninsular. Como demuestran los nuevos datos arqueológicos, el proceso de conquista del noroeste durante el cambio de era fue especialmente intenso ${ }^{34}$ y, una vez terminada, el Estado romano generó una red de alianzas con las comunidades locales y de establecimientos que aseguraron su poder durante los siguientes siglos ${ }^{35}$. Ciudades como Bracara Augusta, Chaves, Lucus Augusti, o Asturica Augusta, junto con importantes vías romanas como la Vía XVIII -que conectaba Astorga con Braga- fueron nodos centrales de la articulación de los intereses romanos en este territorio, vinculados fundamentalmente -pero no exclusivamente- a la minería romana del entorno de Las Médulas ${ }^{36}$. Por su parte, el mundo rural se vería modificado muy sustancialmente con el abandono de numerosos castros ocupados durante los siglos precedentes, un fenómeno documentado en prácticamente todos los contextos conocidos y que permite hablar, como veremos, de una reocupación de estos entornos en siglos posteriores ${ }^{37}$. Este sería el caso de sitios como Formigueiros o Viladonga, cuyo abandono se podría datar entre finales del siglo i y los inicios del siglo II d.n.e., a tenor de las recientes revisiones estratigráficas de ambos contextos ${ }^{38}$. Otros castros, en cambio, parecen mostrar signos de continuación en su ocupación durante estos siglos, siendo nodos centrales en la articulación territorial del Imperio, caso, por ejemplo, de Castro Avelhãs (Bragança) ${ }^{39}$.

Si bien el impacto de la crisis en la explotación minera de Las Médulas en la tercera centuria tuvo que ser especialmente intensa en sus alrededores inmediatos ${ }^{40}$, no parece

32 Pérez Losada, Entre a cidade e a aldea.

33 González Ruibal, Galaicos.

34 Costa García, José Manuel; Fonte, João y Gago, Manuel. «The reassessment of the Roman military presence in Galicia and northern Portugal through digital tools: archaeological diversity and historical problems». Mediterranean Archaeology and Archaeometry, 2019, vol. 19, n. o 3, pp. 17-49.

35 Pérez Losada, Entre a cidade e a aldea.

36 Sánchez-Palencia Ramos, Franscisco Javier (ed.). Las Médulas (León): un paisaje cultural en la "Asturia Augustana». León: Diputación de León, 2000; Sastre Prats, Inés. "Estructura de explotación social y organización del territorio en la civitas Zoelarum». Gerión, 1999, vol. 17, pp. 345-359.

37 Para un análisis en profundidad de este fenómeno ver Tejerizo García, Carlos y Canosa Betés, Jorge. «Power, control and social agency in post-roman northern Iberia: an archaeological analysis of hillfort occupations». Journal of Medieval Iberian Studies, 2018, vol. 10, n. o 3, pp. 295-323.

38 Fernández Pereiro et al., "Asentamentos fortificados»; Tejerizo García, Carlos; Rodríguez González, Celtia y Fernández Pereiro, Mario. "¿Continuidad o discontinuidad en los castros del noroeste? Una revisión del yacimiento de Viladonga (Castro de Rei, Lugo)». SPAL, 2019, vol. 28, n. ${ }^{2}$, pp. 279-313.

39 Tereso, Sofia; Brito, André; Umbelino, Cláudia; Cipriano, Miguel; André, Clara y Carvalho, Pedro C. «Arqueologia funerária alto medieval da Torre Velha (Castro de Avelas, Bragança)». En Quirós Castillo, Juan Antonio y Castellanos, Santiago (eds.). Identidad y etnicidad en Hispania. Propuestas teóricas y cultura material en los siglos V-VIII. Bilbao: Universidad del País Vasco, 2015, pp. 146-160.

40 Rodríguez FERNÁNDEZ, «El fin del mundo fortificado». 
que este evento tuviese una particular incidencia en cuanto al poblamiento rural del interior de la provincia de Gallaecia se refiere ${ }^{41}$. Los datos arqueológicos parecen mostrar una cierta homogeneidad con los principales procesos que ocurren en toda la meseta norte. Así, para el siglo IV d.n.e. se documenta la construcción -o ampliación de estructuras anteriores- de villas romanas que parecen gestionar extensos territorios de fondo de valle, como ocurre con Doncide (Pol, Lugo), muy próximo al asentamiento de Viladonga (Castro de Rei, Lugo) ${ }^{42}$, la villa de La Cigarrosa (A Rúa, Ourense), en pleno territorio de Valdeorras ${ }^{43}$, o los nuevos datos provenientes de Proendos (Ourense), donde un impresionante conjunto de estructuras documentadas por georradar mostrarían un establecimiento rural muy intenso en esta zona de la tierra de Lemos, con varias estructuras que corresponderían a época romana ${ }^{44}$.

Junto con estas grandes villas, se han documentado arqueológicamente varios establecimientos secundarios que complementarían la ocupación del mundo rural en el territorio ${ }^{45}$. Uno de los mejores ejemplos conocidos dentro de nuestra zona de estudio sería el poblado de A Proba (O Barco de Valdeorras, Ourense). En este yacimiento, localizado y excavado en el contexto de unas obras en 1991, se documentó un tramo de calzada romana -posiblemente de la vía XVIII- asociado a un sistema de canalizaciones de gran envergadura junto con diversos muros de mampostería que podrían corresponder a viviendas ${ }^{46}$. El estudio del material arqueológico parece mostrar una ocupación centrada entre el siglo I y la segunda mitad del IV d.n.e., con dudas de si llega a cruzar la quinta centuria ${ }^{47}$.

41 Gallaecia, en cuanto provincia romana, fue creada como consecuencia de las reformas del emperador Caracalla en el 214 d.n.e., como subdivisión de la antigua provincia Tarraconense.

42 Arias Vilas, Felipe. "Apuntes sobre a ocupación do territorio na Galicia baixorromana: castros e vilas». En Galicia: da romanidade á xermanización. Problemas históricos e culturais. Actas do encontro cientifico en homenaxe a Fermin Bouza Brey (1901-1973). Santiago de Compostela: Museo do Pobo Galego, 1993, pp. 201-208.

43 Veiga Romero, Ana M. a. "Los mosaicos de A Cigarrosa. Historia de un hallazgo». Museo Arqueolóxico Provincial de Ourense, 2009.

44 Fernández Pereiro et al., "Asentamentos fortificados». Agradezco a Francisco Alonso Toucido las referencias sobre este hallazgo, aún inédito. Un adelanto puede consultarse en https://www. lavozdegalicia.es/noticia/lemos/sober/2020/01/18/georradar-descubre-gran-edificio-epoca-romanaproendos/0003_202001M18C3991.htm [consultado el 5 de febrero de 2020].

45 PÉrez Losada, Entre a cidade e a aldea.

46 Soto Arias, Purificación. «Estudio de un asentamiento romano ligado a la vía XVIII en el Valle de Valdeorras (Ourense)». Minius, 1993, vol. II-III, pp. 53-81.

47 Menéndez Llorente, Adriángela. "Aportaciones al estudio de la sigillata en la comarca de Valdeorras (Orense)». En Actas del XXII Congreso Nacional de Arqueología. Vigo: Artes Gráficas Galicia, 1995 , pp. 309-312. 


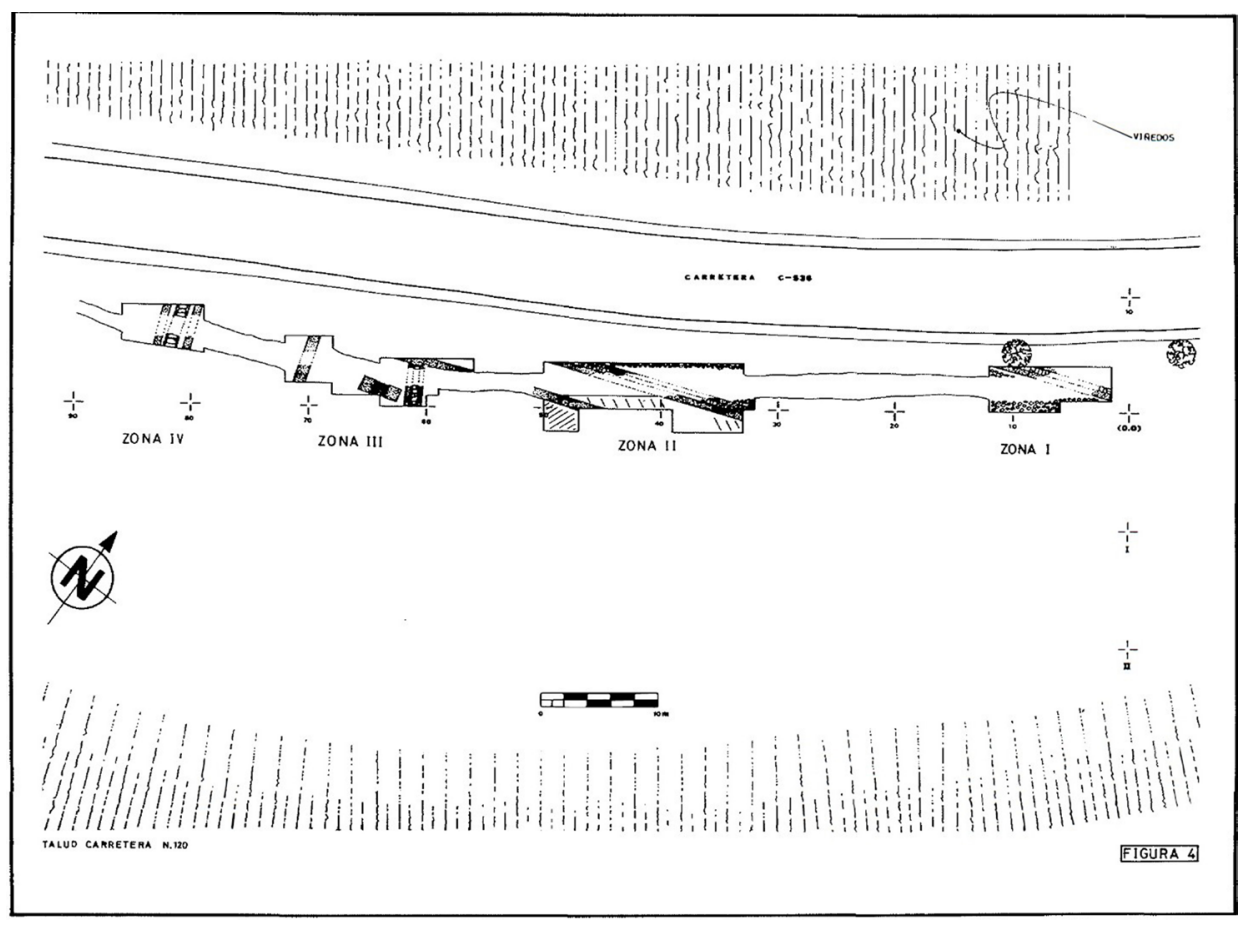

Figura 2. Planimetría del yacimiento de A Proba (O Barco de Valdeorras, Ourense). Fuente: Soto ARIAS, Purificación. "Estudio de un asentamiento romano ligado a la vía XVIII en el Valle de Valdeorras (Ourense)». Minius, 1993, vol. II-III, pp. 53-81.

En resumen, si bien existe una significativa carencia de estudios integrales sobre el mundo rural de época tardorromana y los datos son en general muy dispersos y parcos ${ }^{48}$, todo parece apuntar a un alto grado de desarrollo y organización del poblamiento rural durante este período, articulado en torno a las mismas lógicas que regían en todo el Mediterráneo ${ }^{49}$.

\subsection{La transformación del sistema de poblamiento tardoimperial}

Al igual que los datos arqueológicos mostrarían una importante complejidad en términos de poblamiento asociados a la progresiva implantación de las lógicas imperiales romanas, estos mismos datos sugieren que este esquema de poblamiento tendría un momento de intensas transformaciones entre la segunda mitad del siglo iv y durante el

48 SÁnchez Pardo, «Poblamiento rural».

49 Wicкнам, Chris. The inheritance of Rome: A History of Europe from 400 to 1000. London: Penguin, 2009, capítulo 2 . 
siglo v d.n.e. De estas, podrían destacarse sobre todo tres: las transformaciones en las ciudades y las villas tardoimperiales; la reocupación de los asentamientos fortificados; y la aparición en el paisaje de nuevas formas de poblamiento rural. Pasaremos a describir brevemente algunos aspectos particulares de cada una de ellas.

La arqueología urbana de época tardoimperial en Galicia ha tenido un desarrollo desigual. Si bien se ha realizado una muy significativa cantidad de intervenciones en las principales ciudades gallegas, los análisis y divulgación de resultados han sido en general muy escasos y dispersos, y apenas existen trabajos de síntesis sobre estos datos ${ }^{50}$. En el interior de la Gallaecia, Lugo es quizá el caso más conocido, mostrando un claro panorama de transformaciones que podrían datarse en los siglos iv y v d.n.e., que incluirían reformas en la muralla ${ }^{51}$, el progresivo desmantelamiento y abandono de las lujosas casas de las élites urbanas, como ocurre en el caso de la conocida Domus de Mitreo o el abandono de algunas zonas productivas, como los hornos de la cerámica engobada tan característica de la capital lucense, que se reestructurarían en nuevos focos productores de cerámica gris $^{52}$. Por su parte, las fases más tardías de las villas del interior del territorio de Gallaecia apenas son conocidas. De sitios como Doncide, La Cigarrosa o la domus de Pedreiros de Lago (Carucedo, León) poco más se puede afirmar, por el momento, que estuvieron ocupadas muy probablemente durante el siglo iv d.n.e. y que no parecen mostrar fases más tardías de los siglos $\mathrm{v}$ y vi d.n.e.

Quizás el proceso vinculado a las dinámicas de poblamiento que más impacto ha tenido en el paisaje es el de la reocupación de los asentamientos fortificados. Su análisis estuvo en ocasiones muy apegado a los estudios de las fases prehistóricas de la llamada cultura castrexa $a^{53}$; sin embargo, ya desde hace tiempo se están individualizando y particularizando las problemáticas vinculadas a las ocupaciones tardoimperiales y altomedievales $^{54}$. Las recientes investigaciones revelan dos aspectos de interés. Por un lado, la revi-

50 Nión Álvarez, Samuel. «Brigantium no século xxi: aproximación aos últimos datos arqueolóxicos da ocupación galaicorromana na cidade de A Coruńa (s. I-IV d. C.)». Gallaecia, 2018, vol. 37, pp. 39-79.

51 Alcorta Irastorza, Enrique J. «Muralla romana de Lugo. Novedades en el trienio 2000-2003». En Morillo Cerdán, Ángel (ed.). Producción y abastecimiento en el ámbito militar. Arqueología militar romana en Hispania II. León: Universidad de León, 2006, pp. 601-623.

52 Rodríguez Lovelle, Mónica y López Quiroga, José. «El poblamiento rural en torno a Lugo en la transición de la antigüedad al feudalismo (ss. v-x)». Cuadernos de Estudios Gallegos, 2000, vol. 47, n. ${ }^{\circ} 113$, pp. 53-76; Alcorta Irastorza, Enrique J. y Bartolomé Abraira, Roberto. «Muestras de cerámica engobada romana de producción local de Lucus Augusti (Lugo)». En Bernal Casasola, Darío y Ribera i Lacomba, Albert (eds.). Cerámicas hispanorromanas II. Producciones regionales. Cádiz: Universidad de Cádiz, 2012, pp. 699-724; Fernández Fernández, Adolfo y Bartolomé Abraira, Roberto. «Cerámicas tardoantiguas en el noroeste de la Península (Galicia y norte de Portugal): entre la importación y el artesanado local/regional». En Quirós Castillo, Juan Antonio y Vigil-Escalera Guirado, Alfonso (eds.). La cerámica de la Alta Edad Media en el cuadrante noroeste de la Peninsula Ibérica (siglos V-X). Sistemas de producción, mecanismos de distribución y patrones de consumo. Bilbao: Universidad del País Vasco, 2016, pp. 69-111.

53 Rodríguez Sánchez, "O proceso de abandono dos castros».

54 Tejerizo García, "¿Continuidad o discontinuidad?»; SÁnchez Pardo, "Castros y aldeas galaicorromanas»; SÁNchez PARdo, José Carlos. «Castros, castillos y otras fortificaciones en el paisaje sociopolítico de Galicia (siglos IV-Xi)». En Quirós Castillo, Juan Antonio y Tejado Sebastián, José María (eds.). Los castillos altomedievales en el noroeste de la Península Ibérica. Bilbao: Universidad del País Vasco, 2012, pp. 2956; Fernández Pereiro, Recintos fortificados en altura; Arias Vilas, «Poblamiento rural». 
sión estratigráfica de algunas ocupaciones fortificadas, como Viladonga o Castro Ventosa (Cacabelos/Pieros, León), han permitido centrar sus fases tardías entre los momentos finales del siglo IV d.n.e. y los primeros compases del siglo vi d.n.e. ${ }^{55}$ Por otro lado, las recientes excavaciones en contextos fortificados, como Santomé (Ourense), Viladonga o O Castelo (Valencia do Sil, Vilamartín de Valdeorras, Ourense), han mostrado no solo su importante complejidad urbanística en época tardoimperial ${ }^{56}$, fruto de una planificación lejos de ocupaciones puntuales o de urgencia, sino también la presencia de distintos entornos productivos en su interior, destinados a la fabricación de cerámica, objetos de hierro o, como se ha observado indirectamente a través de las escorias presentes en Castro Ventosa, de vidrio. Más aún, la importante acumulación de numerario que se ha documentado en Viladonga o en el sitio de Penadominga (Bendillo, Lugo) ${ }^{57}$, junto con significativos conjuntos de adornos personales ${ }^{58}$, vincularía estos contextos, al menos parcialmente, con la presencia de ciertos grupos de poder del momento. En el contexto de la profunda transformación de los principales ejes de articulación del Imperio Romano, como son la ciudad, parte de las aglomeraciones secundarias y la villa, la (re)ocupación de estos contextos fortificados en el período IV-VI d.n.e. podría responder a los procesos de adaptación y resiliencia de las élites rurales al nuevo contexto político, tal y como se ha propuesto para el conjunto de asentamientos fortificados de la meseta norte ${ }^{59}$.

Sin embargo, tanto las cronologías como el nivel de calidad de ciertos aspectos materiales, como son las murallas o los contextos productivos documentados, mostrarían algunas particularidades con respecto a los contextos documentados en la meseta norte. Aunque faltan todavía datos precisos sobre la estratigrafía y secuencia de ocupación de estos contextos, los casos anteriormente mencionados $-y$ mejor conocidos- parecen mostrar cronologías de la primera ocupación más tempranas, situadas a finales del siglo IV d.n.e. -si no incluso a mediados de esa centuria-, en comparación a entornos mejor conocidos de la meseta norte ${ }^{60}$, ocupados fundamentalmente en la quinta centuria; esto es, una o quizá dos generaciones antes. Las razones para esta ocupación más temprana podrían estar relacionadas con las particularidades políticas y sociales del territorio de la Gallaecia y del extremo norte peninsular, como comentaremos más adelante.

55 Tejerizo García, Carlos y Vigil-Escalera Guirado, Alfonso. «Castro Ventosa y La Cabeza de Navasangil: una revisión de sus secuencias de ocupación y del fenómeno de los asentamientos fortificados altomedievales». Nailos, 2017, vol. 4, pp. 129-161; Tejerizo García, Carlos; Rodríguez GonzÁlez, Celtia y Fernández Pereiro, Mario. «Materiais cerámicos tardíos (ss. Iv-vi d. C.) no castro de Viladonga». CROA. Boletín da Asociación de Amigos do Museo do Castro de Viladonga, 2018, vol. 28, pp. 36-52.

56 Rodríguez González, Xulio y Xusto Rodríguez, Manuel. Santomé. Conxunto arqueolóxico natural. Ourense: Xunta de Galicia, 2019.

57 Durán Fuentes, María Consuelo. Moedas do Museo do Castro de Viladonga. Santiago de Compostela: Xunta de Galicia, 2009; Cepeda, Juan José. «Monedas procedentes del castro de Penadominga (Bendollo, Quiroga. Lugo)». Numisma, 1993, vol. 232, pp. 91-107.

58 Lage Pillado, Manuel. Fíbulas galaico-romanas do Castro de Viladonga. Santiago de Compostela: Xunta de Galiza, 2004.

59 Tejerizo García y Canosa Betés, «Power, control and social agency»; Quirós Castillo, Juan Antonio. «Introducción». En Quirós Castillo y Tejado Sebastián (eds.), Los castillos altomedievales, pp. 17-27.

60 Sastre Blanco, José Carlos; Fuentes Melgar, Patricia y Catalán Ramos, Raúl. Las fortificaciones en la tardoantigüedad. Élites y articulación del territorio (siglos V-VIII d. C.). Madrid: La Ergástula, 2014. 


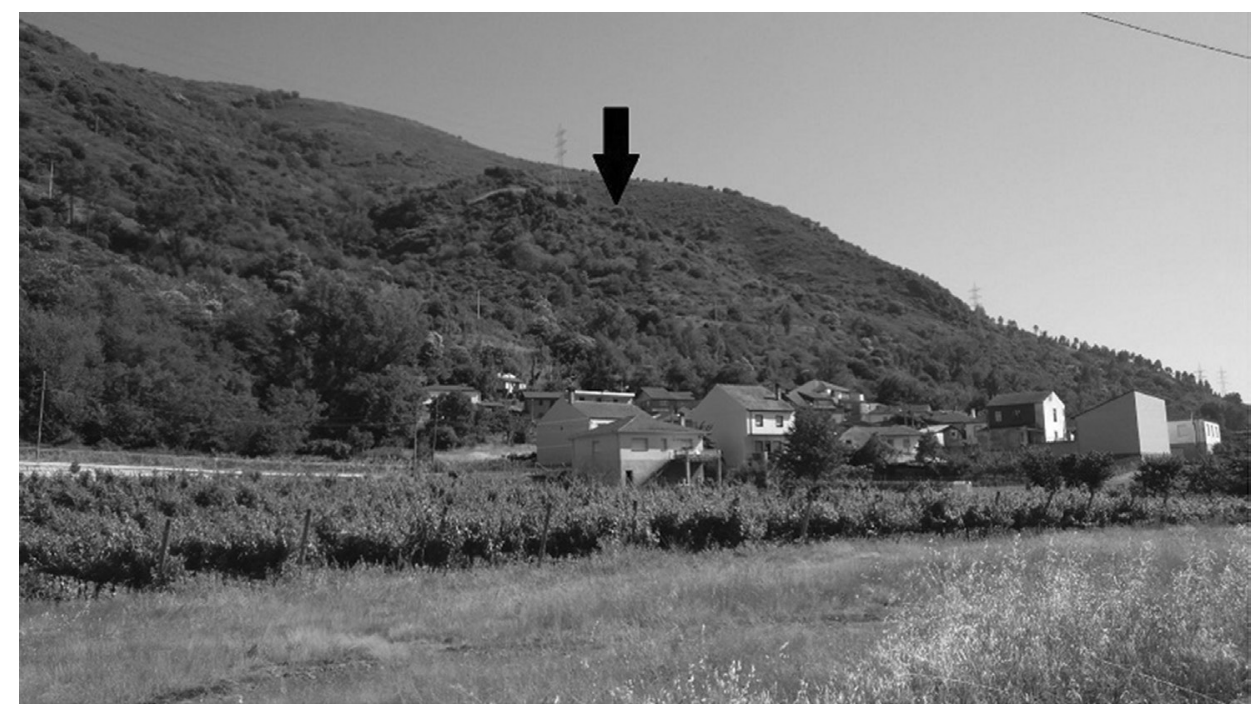

Figura 3. Yacimiento de Valencia do Sil (Vilamartín de Valdeorras, Ourense). Fuente: propia.

Paralelamente al proceso de ocupación de estos entornos fortificados en altura relativa, nos encontramos en el registro con algunos asentamientos rurales en abierto. Este sería el ejemplo del particular yacimiento de Foxas da Chá (Bóveda, Lugo). Localizado durante el seguimiento de construcción de una vía de ferrocarril, se documentaron un total de 35 manchas en el suelo de formatos circulares, de las cuales se excavaron un total de tres que podrían corresponder con silos de almacenamiento. El escaso material recuperado del asentamiento (14 fragmentos cerámicos) presenta algunas formas características de cerámica engobada tardía, concretamente cuencos tipo 18T según la tipología de E. Alcorta, datados entre los siglos iv y v d.n.e. ${ }^{61} \mathrm{La}$ presencia de silos de almacenamiento asociados a este material parece corresponderse con el tipo de asentamientos documentados en otros contextos de la meseta norte y el centro peninsular que en otros trabajos se denominaron como "aldeas de primera generación» ${ }^{62}$. Otro asentamiento rural en abierto similar sería el de Os Castros (Mondoñedo, Lugo). En el año 2017 se realizaron 9 zanjas y 5 sondeos con el objetivo de documentar posibles estructuras arqueológicas en este entorno. Concretamente, en el sondeo denominado Z-06 se documentó un muro de mampostería perteneciente a una estructura asociada a construcciones rehundidas que, por el material asociado, podría datarse en los siglos v y vi d.n.e. ${ }^{63}$

${ }^{61}$ Alcorta Irastorza, Enrique J. Lucus Augusti (vol. II): cerámica común de cocina y mesa hallada en las excavaciones de la ciudad. A Coruña: Fundación Pedro Barrié de la Maza, 2001; Alcorta Irastorza y Bartolomé Abraira, «Muestras de cerámica engobada».

62 Tejerizo García, Carlos. Arqueología de las sociedades campesinas en la cuenca del Duero durante la Primera Alta Edad Media. Bilbao: Universidad del País Vasco, 2017.

63 Vigo García, Abel. Intervención arqueolóxica en Os Castros (Mondoñedo, Lugo). Memoria técnica inédita, 2017. 
EL POBLAMIENTO EN EL INTERIOR DE LA GALLAECIA ENTRE EL FINAL DEL IMPERIO ROMANO Y LA ALTA EDAD MEDIA: NUEVOS DATOS, NUEVAS PROPUESTAS

CARLOS TEJERIZO GARCÍA

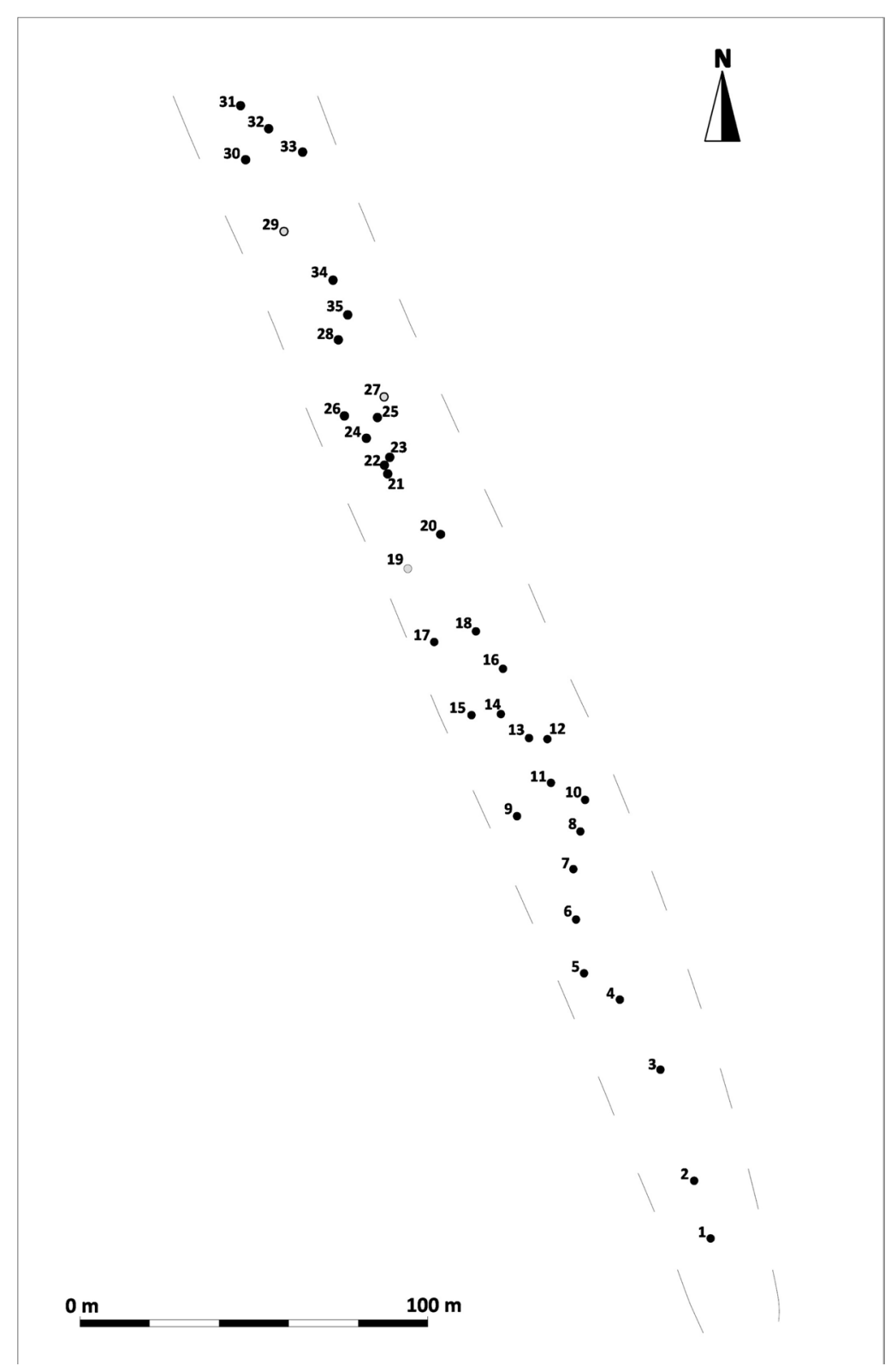

Figura 4. Planimetría del yacimiento de Foxas da Chá (Bóveda, Lugo). Fuente: elaboración propia a partir de la ficha del inventario elaborada por Iván A. Álvarez Merayo y consultada en la Dirección Xeral de Patrimonio (Santiago de Compostela). 


\subsection{Granjas y aldeas en el interior de la Gallaecia: algunos apuntes}

Hasta muy recientemente, el análisis sobre el poblamiento rural entre el final del Imperio Romano y la Alta Edad Media se movía en un pantanoso terreno entre la parcialidad y la especulación, producido principalmente por la escasez de datos tanto arqueológicos como documentales ${ }^{64}$. Como escribía J. C. Sánchez Pardo: «siendo muy estrictos podríamos decir que desde el final de la cultura castreña (en torno a los siglos i y iI) hasta finales de la alta edad media (siglos IX-XI) no poseemos datos que nos permitan reconstruir con cierta seguridad el patrón de poblamiento rural y organización territorial» ${ }^{65}$. Sin embargo, la progresiva incorporación de los datos provenientes de las intervenciones de urgencia -en muchos casos vinculadas a la llamada "arqueología de la gasificación» ${ }^{66}$ - así como la revisión de las estratigrafías de algunos yacimientos específicos están permitiendo documentar procesos muy similares a los reconocidos en otros territorios. Uno de los más significativos en este sentido es el de la emergencia de las aldeas altomedievales. En las últimas dos décadas se han excavado varios contextos de gran interés para el análisis de este proceso en el noroeste peninsular, algunos de los cuales se expondrán aquí brevemente a modo de ejemplos.

Un caso especialmente interesante sería el del yacimiento de Casanova (Abadín, Lugo ${ }^{67}$. Este yacimiento fue localizado por primera vez en 1998 , cuando se documentaron ocho estructuras de perfil rehundido durante unas obras vinculadas a la instalación de una línea de gas. Una de estas estructuras fue sondeada, dando como resultado la exhumación de material que fue descrito como «medieval». Como consecuencia de la construcción de una autovía (la actual AP-8), se realizaron hasta dos campañas de excavación en los ańos 2008 y 2009, con la documentación y excavación selectiva de hasta 120 estructuras, que incluyeron varios edificios con cimentación de piedra, fondos de cabaña, silos de almacenamiento y fosas indeterminadas. Más aún, se documentó un interesante conjunto de tres tumbas hechas a base de lajas de pizarra y tégulas imbricadas, vinculadas a una de las estructuras con cimentación de piedra y que se presentarían como uno de los primeros casos de este tipo de tumbas asociadas a unidades domésticas en ámbito rural documentadas en el noroeste ${ }^{68}$. El análisis de los materiales exhumados permitió diferenciar dos fases principales: una primera de la II Edad del Hierro -atestiguado

64 Rodríguez FernÁndeZ, «El fin del mundo fortificado».

65 SÁnChez PARDo, «Poblamiento rural tardorromano».

66 Criado Boado, Martínez López y Amado Reino, La arqueología en la gasificación de Galicia.

${ }_{67}$ Morchón Viñas, Javier. Informe valorativo 1. Excavación arqueológica en área en el yacimiento de Casanova, GA27001016 Castromaior, S. Xoán de Castromaior (Abadín, Lugo). Informe inédito depositado en el Museo de Viladonga, 2008; Morchón Viñas, Javier. Informe valorativo 2. Excavación arqueológica en área en el yacimiento de Casanova, GA27001016 Castromaior, S. Xoán de Castromaior (Abadin, Lugo). Informe inédito depositado en el Museo de Viladonga, 2009.

68 Blanco Torrejón, Laura. «Entre lo pagano y lo cristiano. Espacios funerarios romanos y tardoantiguos en Galicia». Gallaecia, 2018, vol. 37, pp. 81-102. 
principalmente por la presencia de una fíbula de tipo transmontano- y una segunda adscrita a un período indeterminado «romano-medieval». Entre el material cerámico se documentó un amplio conjunto de cerámicas de cocciones reductoras (cerámicas grises) así como formas de ollas con perfiles en $S$ y cuencos carenados que, por su comparativa con materiales contemporáneos de contextos de la meseta norte ${ }^{69}$, nos permitió concluir que esta segunda fase podría datarse principalmente entre los siglos vi-viI d.n.e. ${ }^{70}$ Estas cronologías junto con el tipo de estructuras exhumadas permitirían interpretar el conjunto de Casanova como una aldea, formada por al menos tres unidades domésticas, muy similar a las localizadas en la cuenca del Duero o en Madrid ${ }^{71}$.

Otro interesante yacimiento sería el de As Pereiras (Amoeiro, Ourense). Este yacimiento, excavado en 1998 en el contexto de un control de la construcción de la Red de Gasificación de Galicia, fue catalogado como «romano-medieval» debido a las dificultades para la identificación de los materiales ${ }^{72}$. La excavación de un sondeo en el sitio deparó la documentación de un muro asociado a algunas estructuras rehundidas. Al igual que en el sitio de Casanova, la aparición de material prehistórico permitió diferenciar varias fases de ocupación, la segunda de las cuales fue aproximada por los excavadores a los siglos v y vir d.n.e. a partir de la presencia de un singular broche de cinturón de placa calada $^{73}$. La revisión de la estratigrafía y del material asociado nos ha permitido concluir que el contexto contaría, al igual que en el caso de Casanova, con dos fases principales, una centrada en la Prehistoria Reciente (posiblemente del Hierro I) y otra fase de época altomedieval que, por la presencia de ciertas formas de ollas con bordes de pestańa muy poco desarrollados, hemos podido encuadrar entre el siglo viI/viII y el siglo IX/X d.n.e. ${ }^{74}$ Por su parte, el broche -que efectivamente se puede datar en torno a la quinta centuriaapareció en un nivel superior junto con material residual, por lo que se debería considerar que se encuentra en posición secundaria. De hecho, es interesante que en las cercanías del yacimiento de As Pereiras, a kilómetro y medio hacia el nordeste, se localizó otro yacimiento, denominado A Mora, cuyo material publicado tiene una clara adscripción tardorromana ${ }^{75}$. Consideramos entonces que el broche, que se puede datar con cierta seguridad en el siglo v d.n.e. -como acertadamente hacen los excavadores- podría pertenecer a un entorno funerario de este otro contexto, como un ejemplo de necrópolis

69 Vigil-Escalera Guirado, Alfonso y Quirós Castillo, Juan Antonio. La cerámica de la Alta Edad Media en el cuadrante noroeste de la Península Ibérica (siglos V-X). Bilbao: Universidad del País Vasco, 2016; Martín Viso, Iñaki; Fuentes Melgar, Patricia; Sastre Blanco, José Carlos y Catalán Ramos, Raúl. Cerámicas altomedievales en Hispania y su entorno (s. V-VIII). Madrid: Glyphos, 2018.

70 Tejerizo García, Carlos; Alonso Toucido, Francisco y Torres Iglesias, Diego. «Propuesta de secuenciación cerámica en contextos rurales del interior de Galicia desde el Tardoimperio a la Alta Edad Media (ss. v-X/XI d.n.e.)». En prensa.

71 Tejerizo García, Arqueología de las sociedades campesinas; Vigil-Escalera Guirado, Alfonso. "Granjas y aldeas altomedievales al norte de Toledo (450-800 d. C)». Archivo Español de Arqueología, 2007, vol. 80 , pp. 239-284.

72 Aboal Fernández, Roberto y Cobas Fernández, Isabel. «La Arqueología en la Gasificación de Galicia 10: sondeos en el yacimiento romano-medieval de As Pereiras». TAPA, 1999, vol. 13.

73 Ibid.

74 Tejerizo García, Alonso Toucido y Torres Iglesias, «Propuesta de secuenciación».

75 Ibid. 
postimperial, similar a los documentados en la meseta norte y también al que posiblemente se vinculen los materiales de Penadominga ${ }^{76}$.

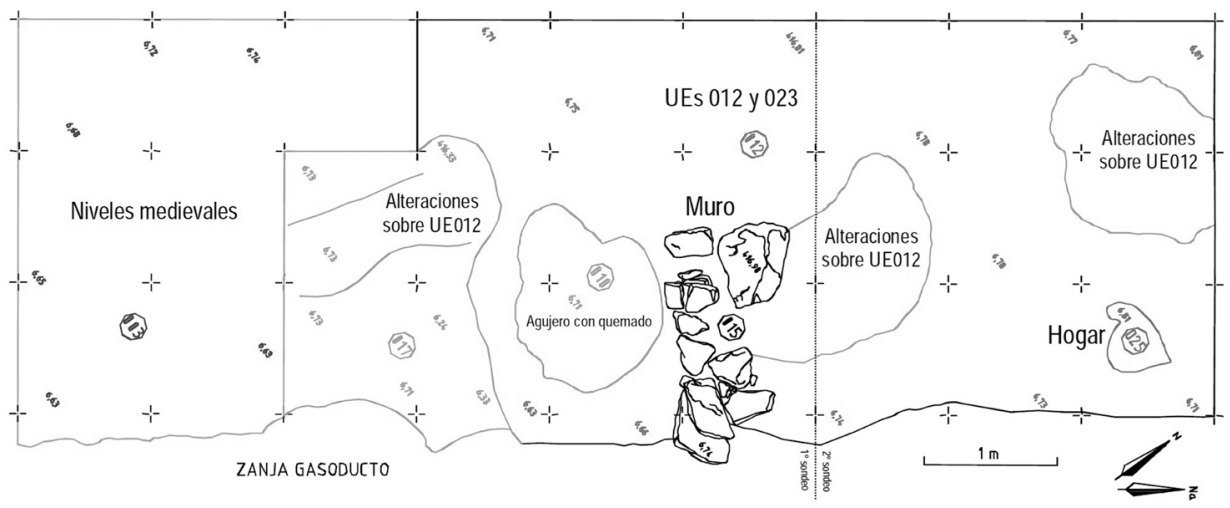

Figura 5. Planimetría del yacimiento de As Pereiras. Fuente: ABOAL FERNÁNDEZ, Roberto y COBAS FERNÁNDEZ, Isabel. "La Arqueología en la Gasificación de Galicia 10: sondeos en el yacimiento romanomedieval de As Pereiras». TAPA, 1999.

El último yacimiento que se comentará es el sitio de A Pousada (Bornais, Santiago de Compostela), localizado durante los trabajos de Evaluación de Impacto de una obra de construcción y excavado en el año $2001^{77}$. En esta excavación se documentó un conjunto de muros de mampostería, correspondientes a varias fases de construcción de una misma unidad doméstica y asociados a algunos silos de almacenamiento, el vestigio más antiguo del yacimiento. Esta primera fase fue datada mediante radiocarbono entre finales del siglo vi y finales del viI d.n.e. ${ }^{78}$, mientras que el abandono de esta construcción se dató en un momento entre el siglo XI y xIII d.n.e. ${ }^{79}$ La revisión estratigráfica y del material arqueológico que pudimos llevar a cabo parece confirmar tanto la secuencia general como el momento de abandono en torno al siglo xI d.n.e., si bien las primeras fases de ocupación parecen aproximarse al último momento de la séptima centuria o ya en la octava, coincidiendo con el intervalo más moderno de la datación radiocarbónica. El yacimiento de A Pousada, interpretado como una granja altomedieval, mostraría de nuevo la complejidad del sistema de poblamiento en este período además de una singular

76 Fernández Pereiro et al., «Asentamentos fortificados».

77 Blanco Rotea, Rebeca; Prieto Martínez, M. ${ }^{a}$ Pilar; Ballesteros, Paula y López González, Luis F. "Capítulo 11. El despoblado de A Pousada: la formación de una aldea rural en la Alta Edad Media». En Prieto Martínez, M. a Pilar y Criado Boado, Felipe (eds.). Reconstruyendo la historia de la comarca del Ulla-Deza (Galicia, España). Escenarios arqueológicos del pasado. Santiago de Compostela: Consejo Superior de Investigaciones Científicas, 2009.

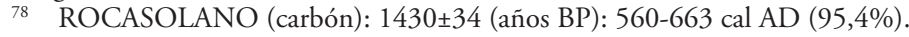

79 El momento de ocupación de la estructura fue datada mediante un carbón localizado en el interior de un agujero de poste. CSIC-1861: $1349 \pm 26$ (años BP): 642-716 cal AD (89,8\%); 748-764 cal AD (5,6\%). 
estabilidad territorial, sobre todo en lo que concierne a la octava centuria, como luego comentaremos.

De estos casos cabrían destacar tres cuestiones principales. En primer lugar, reiterar la complejidad del poblamiento rural altomedieval, conformado por la presencia, más numerosa de lo que habitualmente se ha considerado, de aldeas y granjas distribuidas por el territorio del interior de la antigua Gallaecia durante el período a partir del siglo vi d.n.e. en adelante, algo que ya se había sugerido con anterioridad pero que no estaba atestiguado arqueológicamente ${ }^{80}$. En segundo lugar, en el caso de A Pereira la presencia de un potencial yacimiento de época tardorromana en el entorno, pero también distanciado y en el que, por el momento, no hay superposiciones, lo que indicaría una posible ruptura del sistema de poblamiento entre la quinta y la séptima centuria, similar a lo reconocido en otros contextos de la meseta norte o de yacimientos de Madrid, como El Pelícano (Arroyomolinos) ${ }^{81}$. Por último, el caso de As Pereiras, junto al de A Pousada, podrían sugerir una significativa continuidad en el sistema de poblamiento rural a partir del siglo viI hasta, por lo menos, el siglo $\mathrm{x}$ d.n.e.

\subsection{La estructuración social del paisaje altomedieval}

Todas estas evidencias sugerirían, por lo tanto, un poblamiento altomedieval constituido principalmente a través de la articulación de granjas y aldeas que se distribuirían a lo largo del territorio del interior de la antigua provincia de Gallaecia. Sin embargo, su inserción en las redes de poder de época altomedieval es una cuestión apenas esbozada en la actualidad. Los análisis llevados a cabo por J. C. Sánchez Pardo en torno a las iglesias altomedievales y la formación de las élites en el noroeste peninsular señalan la presencia de potentes grupos económicos y sociales cuya génesis podría rastrearse en la octava centuria e incluso antes ${ }^{82}$. Igualmente, es durante este momento cuando se detecta la presencia de algunas redes de fortificaciones que articularían los territorios en la pequeña escala $^{83}$, procesos que serían, por lo tanto, contemporáneos a la emergencia de estas aldeas y granjas en el territorio.

Sin embargo, aún estamos lejos de tener un cuadro empírico e interpretativo lo suficientemente sólido como para analizar las formas de articulación entre los distintos grupos sociales en el mundo rural del interior de la Gallaecia durante este período. Sí hay, en cambio, algunos elementos arqueológicos interesantes dignos de ser mencionados, en este caso, provenientes del territorio en torno al Sil y, en concreto, de la comarca

80 Rodríguez Fernández, «El fin del mundo fortificado».

81 Tejerizo García, Carlos. "The end of the world as we know it: post-imperial social lanscapes in North-Central Iberia (5th-6th centuries)». Archeologia Medievale, 2016, vol. XLIII, pp. 383-397.

82 Sánchez Pardo, «Power strategies»; Sánchez Pardo, José Carlos; Blanco Rotea, Rebeca y SanJuRJo SÁNCHEZ, Jorge. "The church of Santa Comba de Bande and early medieval Iberian architecture: new chronological results». Antiquity, 2017, vol. 358, pp. 1011-1026.

83 Fernández Pereiro, Recintos fortificados; Sánchez Pardo, José Carlos y Galbán Malagón, Carlos J. «Fortificaciones de altura en el entorno de Santiago de Compostela. Hacia un primer análisis arqueológico comparativo». Nailos, 2014, vol. 2, pp. 125-161. 
EL POBLAMIENTO EN EL INTERIOR DE LA GALLAECIA ENTRE EL FINAL DEL IMPERIO ROMANO Y LA ALTA EDAD MEDIA: NUEVOS DATOS, NUEVAS PROPUESTAS CARLOS TEJERIZO GARCÍA

de Valdeorras. En concreto cabría mencionar dos. En primer lugar, en este territorio se documenta una significativa concentración de elementos arquitectónicos en mármol de calidad datados de forma amplia en época visigoda y altomedieval. Concretamente serían siete los que hasta el momento se han podido localizar, que incluirían el conocido crismón de Quiroga, interpretado como un altar del siglo vi d.n.e. ${ }^{84}$; un fragmento de cancel reutilizado actualmente en uno de los muros de la ermita de Santa María de Mones $(\text { Petín })^{85}$; otro cancel decorado, actualmente reutilizado como dintel en una bodega de la aldea de Petín ${ }^{86}$; un capitel exento localizado en el muro de una vivienda particular en Petín ${ }^{87}$; otro capitel exento, que se encuentra en la iglesia de Valencia do Sil (Vilamartín de Valdeorras) ${ }^{88}$; otro capitel exento localizado en los entornos de Quiroga; y, finalmente, un último capitel decorado con motivos vegetales localizado en el arco del muro oriental de la nave principal de la iglesia de San Miguel de Xagoaza (O Barco de Valdeorras) ${ }^{89}$.

Aunque se trata de elementos aislados en el paisaje y ninguno de ellos está en su posición original, todos ellos pueden datarse en este intervalo entre los siglos vi y $\mathrm{Ix} / \mathrm{x}$ d.n.e., lo que mostraría una llamativa concentración de elementos de prestigio durante este período, sobre todo si lo ponemos en comparación con otros territorios en el mismo período $^{90}$. La diferente factura y el material de cada uno de ellos mostraría, potencialmente, la presencia de varios edificios de prestigio repartidos en este territorio y, con ello, la presencia de grupos de poder capaces de acaparar el suficiente capital social, económico y simbólico para su construcción, lo que cuadraría con la imagen general de una élite poderosa en el noroeste en el período post-romano ${ }^{91}$.

El otro elemento arqueológico de interés estaría representado por la presencia de un número muy elevado de cecas de época visigoda en el noroeste peninsular. Como ya han señalado otros autores, estas cecas corresponden en ocasiones a pequeńos núcleos rurales que, eventualmente, se convertían en centros de producción monetaria ${ }^{92}$. Este sería el caso, por ejemplo, de Casaio (Carballeda de Valdeorras), donde se ha localizado una de estas cecas gracias a una moneda de época de Suintila con la inscripción Cassavio. El núcleo de Casaio se localiza en los escarpados valles de la Serra do Eixe, y se trataría, a primera vista, de un entorno periférico, donde las comunicaciones serían especialmente

84 Sánchez Pardo, José Carlos. "Crismón de Quiroga». En Villares, Ramón (ed.). 100 Galicia Cen. Obxectos para contar unha cultura. Santiago de Compostela: Consello da Cultura Galega, 2016, pp. 79-81.

85 Fernández Pereiro et al., «Asentamentos fortificados».

86 Ibid.

87 Rodríguez Colmenero, Antonio. Galicia meridional. Bilbao: Universidad de Deusto, 1977.

88 Ibid. 2015.

89 Enciclopedia del románico. Ourense (2 tomos). Aguilar de Campoo: Fundación Santa María la Real,

90 Caballero Zoreda, Luis y Utrero Agudo, María de los Ángeles. Iglesias tardoantiguas y altomedievales en la Península Ibérica. Análisis arqueológico y sistemas de abovedamiento. Madrid: Consejo Superior de Investigaciones Científicas, 2006.

91 SÁnchez Pardo, «Power strategies».

92 Pliego Vázquez, Ruth. La moneda visigoda. (2 vols.). Sevilla: Universidad de Sevilla, 2009; SÁNChez Pardo, José Carlos. «Sobre las bases económicas de las aristocracias en la Gallaecia suevo-visigoda (ca. 530-650 d. C.). Comercio, minería y articulación fiscal». Anuario de Estudios Medievales, 2014, vol. 44, n. ${ }^{\circ}$ 2, pp. 983-1023. 
EL POBLAMIENTO EN EL INTERIOR DE LA GALLAECIA ENTRE EL FINAL DEL

IMPERIO ROMANO Y LA ALTA EDAD MEDIA: NUEVOS DATOS, NUEVAS PROPUESTAS

CARLOS TEJERIZO GARCÍA

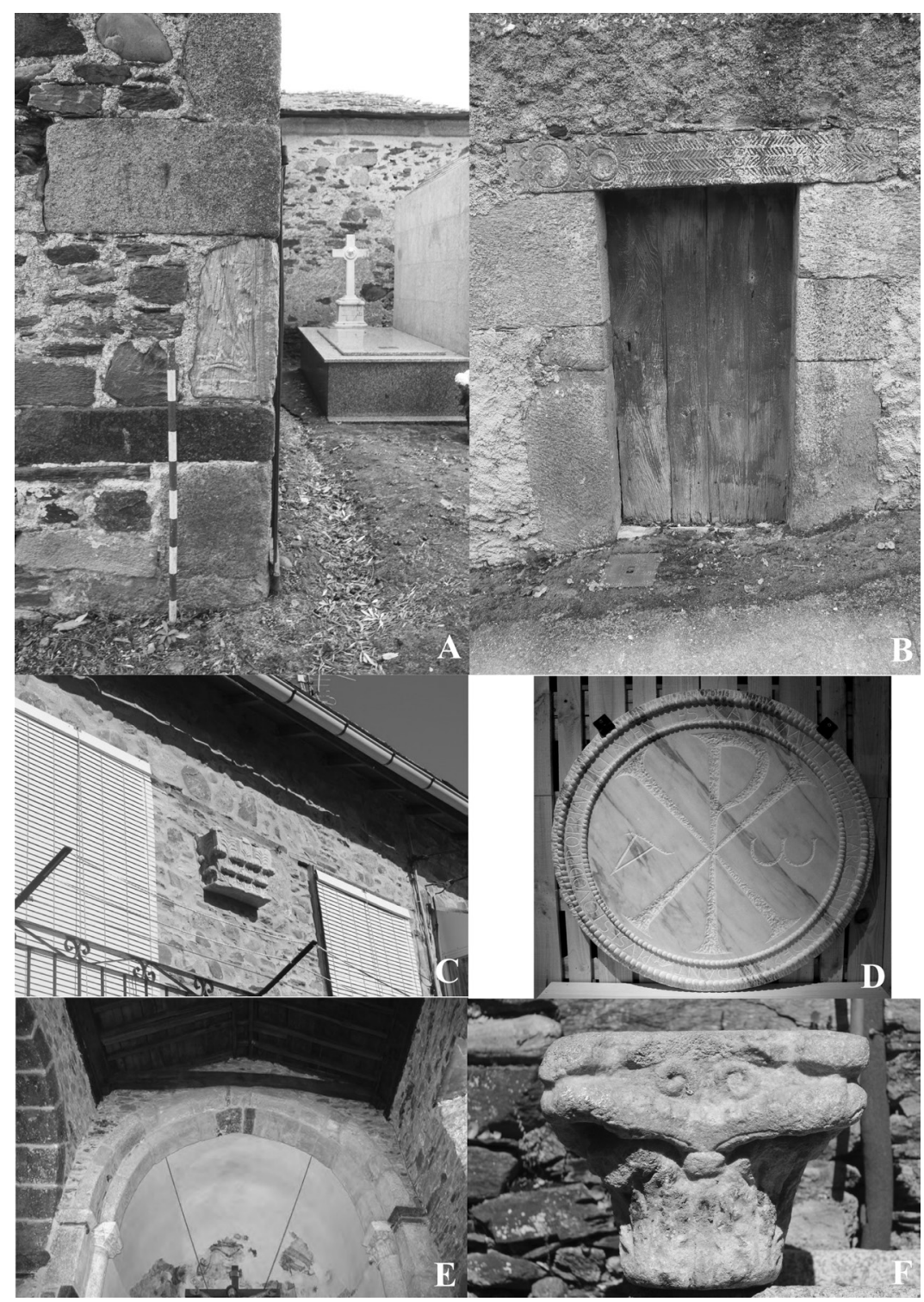

FIGURA 6. Elementos constructivos de prestigio altomedieval localizados en la comarca de Valdeorras. A) cancel en la iglesia de Santa Maria de Mones; B) cancel utilizado como dintel en Petín; C) capitel en vivienda de Petín; D) crismón de Quiroga; E) capitel en la iglesia de San Miguel de Xagoaza; F) capitel exento en Valencia do Sil. Fuente: elaboración con fotografías propias salvo D, extraida de gciencia.com; y E, extraída de Enciclopedia del románico. Ourense (2 tomos). Aguilar de Campoo: Fundación Santa María la Real, 2015. 
difíciles de mantener. Sin embargo, los trabajos de prospección realizados nos llevan a la conclusión de que Casaio era un entorno muy dinámico entre los siglos $\mathrm{v}$ y x d.n.e., con la presencia de un conjunto de asentamientos datados preliminarmente en este período que enmarcarían arqueológicamente la potencial presencia de una ceca.

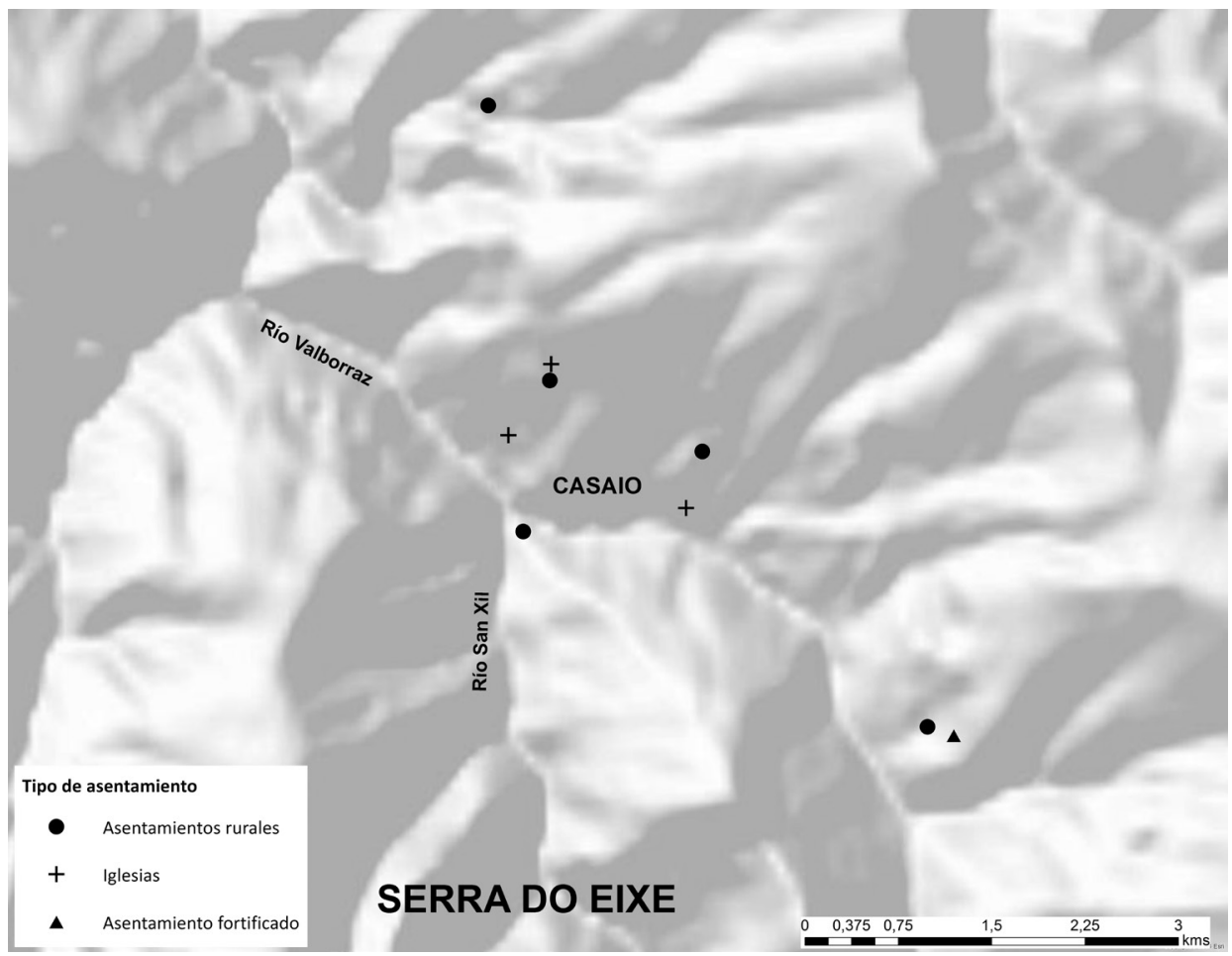

Figura 7. Distribución de yacimientos en torno a Casaio (Carballeda de Valdeorras, Ourense).

Dentro de estos yacimientos, uno de los más interesantes podría ser el de Penedo Xudío, un enclave que ocupa un pequeño promontorio de gran control visual y donde se ha localizado material posiblemente altomedieval, estructuras domésticas asociadas, una necrópolis - de la que se han localizado hasta el momento dos tumbas de lajas- y la posible presencia de numerario de época visigoda asociada al yacimiento ${ }^{93}$. Además, Casaio está mencionada como ecclesia en el Parroquial Suevo, parte de la sede auriense ${ }^{94}$, si bien en lo que se podría considerar una zona periférica dentro de la organización

93 Proveniente de la información oral recogida en Casaio. Si bien aún no tenemos datos sólidos al respecto, hay firmes sospechas, por las descripciones recogidas, de que realmente sea verídico.

94 Sánchez Pardo, José Carlos. «Organización eclesiástica y social en la Galicia tardoantigua. Una perspectiva geográfico-arqueológica del parroquial suevo». Hispania Sacra, 2014, vol. 134, pp. 439-480. 
mostrada por el documento ${ }^{95}$. Por el momento, y con los pocos datos disponibles, sería difícil explicar este conjunto de evidencias altomedievales en un entorno como Casaio, a priori periférico y aislado. Sin embargo, la hipótesis sostenida por J. C. Sánchez Pardo de la vinculación de este tipo de contextos con la revitalización de la minería en época visigoda en el noroeste es, cuanto menos, sugerente ${ }^{96}$.

El Sistema DE POBLAMIENTO EN EL INTERIOR DE LA GALLAECIA: ALgunas CONSIDERACIONES GENERALES

En los últimos años el número de estudios dedicados al poblamiento altomedieval en el noroeste se han multiplicado, gracias tanto a la incorporación de nuevos datos provenientes de proyectos de investigación como al diálogo y convergencia entre las corrientes historiográficas mencionadas al inicio de este trabajo. Tradicionalmente, se había entendido este territorio como marginal, aislado de los principales acontecimientos políticos que caracterizarían a la Península Ibérica en este período. Sin embargo, los estudios sobre el dinamismo del comercio en los siglos V-VII d.n.e. en la costa atlántica ${ }^{97}$, los análisis y dataciones realizadas en las iglesias rurales ${ }^{98}$ o los estudios bioarqueológicos ${ }^{99}$ están abriendo un nuevo horizonte en el que, por el contrario, comienza a entenderse a la Gallaecia como un núcleo político y económico de primer orden. Ambos planteamientos, el del noroeste bien como periferia o bien como centro, tienden a subrayar las particularidades del territorio con respecto a otros; una suerte de excepcionalidad que, en consecuencia, debe analizarse en sus propios parámetros, desvinculada del resto de territorios ${ }^{100}$.

Sin embargo, a tenor de los datos expuestos parece más razonable plantear las transformaciones del poblamiento y la sociedad en Gallaecia en términos comparativos, siguiendo las propuestas de Ch. Wickham ${ }^{101}$, de forma que tanto las semejanzas como las diferencias de este territorio formen parte ecuánime de una interpretación global sobre el sistema de poblamiento y su significado en términos sociales y políticos. Así, a lo largo del texto se han venido subrayando precisamente las semejanzas en el sistema de poblamiento del interior de la Gallaecia con respecto a las dinámicas que se han reconocido en otros territorios peninsulares, fundamentalmente de la meseta norte y del área de Madrid. Los principales elementos que configuran el poblamiento rural en época tardoimperial y altomedieval son reconocibles en todos estos espacios, como son las reocupaciones de asentamientos fortificados, la emergencia de los primeros paisajes campesinos en

95 Díaz Martínez, El Reino Suevo (411-585).

96 SÁNChez PARDo, «Sobre las bases económicas».

97 FERnández FERnÁndeZ, El comercio tardoantiguo.

98 Sánchez Pardo, Blanco Rotea y Sanjurjo Sánchez, "The church of Santa Comba de Bande».

99 López Costas y Muldner, "Fringes of the empire».

100 Torres, Galicia sueva.

101 Wickнам, Chris. «Problemas de comparación de sociedades rurales en la Europa occidental de la temprana Edad Media». Anales de Historia Antigua y Medieval, 1996, vol. 29, pp. 45-70; Wickнам, Chris. Framing the Early Middle Ages. Oxford: Oxford University Press, 2005. 
torno a la quinta centuria o la presencia de un número muy significativo de contextos rurales tipo granjas y aldeas, así como su ruptura con el paisaje inmediatamente anterior, que parecen hegemonizar el paisaje a partir de la sexta centuria. Fenómenos que hasta ahora no habían sido reconocidos en el registro y que ocasionaban ciertos problemas de interpretación de contextos que escapaban a las lógicas historiográficas tradicionales -como, por ejemplo, la categorización como «romano-medieval» de ciertas aldeas altomedievales-. En este sentido, los datos recogidos en el entorno del río Sil y de la comarca de Valdeorras son especialmente interesantes, ya que podrían compararse perfectamente con los territorios mejor conocidos de Cea, el valle del Jarama, el valle del Eresma o el sur de Salamanca ${ }^{102}$.

Esto no quiere decir que en el territorio objeto de estudio no se den ciertas particularidades que lo singularizan en relación con los otros mencionados. Esto no es sino una consecuencia lógica de los cambios de escala que se producen en la Península Ibérica a partir de la quinta centuria y que generan dinámicas locales y territoriales diferenciadas ${ }^{103}$. A partir de los datos expuestos anteriormente, se destacarán aquí fundamentalmente dos de estas particularidades.

En primer lugar, cabe destacar que, hasta donde los datos permiten llegar, las cronologías de ciertos fenómenos, como el de las reocupaciones de asentamientos fortificados, parecen ser anteriores a los casos mejor conocidos de la meseta norte. Así, mientras que este fenómeno parece datarse en este último territorio fundamentalmente dentro de la quinta centuria, entornos como Viladonga o O Castelo parecen mostrar ocupaciones efectivas ya desde la segunda mitad del siglo iv d.n.e., sin mostrar ocupaciones anteriores que permitan hablar de una continuidad de ocupación. Sin duda, sería precipitado hacer afirmaciones muy taxativas sobre las razones para estas diferencias cronológicas, pero sí que se pueden presentar algunas hipótesis interpretativas. Tomando en consideración que estos asentamientos fortificados representan uno de los fenómenos más significativos de ruptura con respecto al paisaje tardoimperial y que podrían vincularse con las agencias de las élites territoriales ${ }^{104}$, parece razonable pensar que en el caso del noroeste peninsular estos mismos factores podrían tener una cronología algo anterior -una o dos generaciones, aproximadamente, con respecto a los territorios de la meseta norte-. Así, podría plantearse que los procesos de desarticulación del entramado político y económico del Imperio Romano se dieron con anterioridad en el interior de la Gallaecia, un territorio

102 ARIÑo GiL, Enrique. «Modelos de poblamiento rural en la provincia de Salamanca (España) entre la antigüedad y la Alta Edad Media». Zephyrus, 2006, vol. 59, pp. 317-357; Fernández Mier, Margarita; Tejerizo García, Carlos y Aparicio Martínez, Patricia. «El territorio de Cea entre la tardo-romanidad y la Alta Edad Media». En Catalán Ramos, Raúl; Fuentes Melgar, Patricia y Sastre Blanco, José Carlos (eds.). Las fortificaciones en la tardoantigüedad. Élites y articulación del territorio (siglos V-VIII d. C). Madrid: La Ergástula, 2014, pp. 159-177; Tejerizo García, Carlos; Carvajal Castro, Álvaro; Marín Suárez, Carlos; Martínez Álvarez, Cristina y Mansilla Hortigüela, Rafael. «La construcción histórica de los paisajes en el sector central de la cuenca del Duero. Primeros resultados de una prospección intensiva». Territorio, Sociedad y Poder, 2015, vol. 10, pp. 39-62; VigiL-Escalera Guirado, «Granjas y aldeas altomedievales».

103 Escalona Monge, Julio. «The Early Middle Ages: a scale-based approach». En Escalona MonGE, Julio y Reynolds, Andrew (eds.). Scale and scale change in the Early Middle Ages. Exploring landscape, local society, and the world beyond. Turnhout: Brepols, 2011, pp. 9-30.

104 Tejerizo García y Canosa Betés, «Power, control and social agency». 
periférico dentro de los intereses centrales de las élites imperiales, sobre todo después de que la actividad minera descendiese a partir de la tercera centuria -lo que no implica que desapareciese ${ }^{105}-$. Las perturbaciones políticas de finales del siglo iv e inicios de la quinta centuria y la introducción en este contexto de nuevos agentes políticos -las élites bárbaras fundamentalmente-, pugnando por cuotas de poder político y económico en este territorio, podrían explicar el clima de inseguridad necesario para las transformaciones detectadas en el registro arqueológico. Si miembros de la élite tardoimperial, como Hidacio -cuya conocida mención a los castella tutiora data del $430^{106}$-, presentan este clima de incertidumbre dentro de las élites tardoimperiales ya a inicios del siglo $\mathrm{v}$, no es de extrańar que su origen pueda ya detectarse en los momentos precedentes. Acontecimientos sociales, políticos y económicos que se darían más tarde en aquellos territorios mejor controlados por el poder imperial romano, como la meseta norte.

Siguiendo esta lógica, también cabría contextualizar el papel de estos entornos fortificados, caso de O Castelo o Castro Ventosa, dentro de las lógicas del emergente estado suevo. En el proceso de consolidación política y territorial de este nuevo tipo de formación política, estos entornos podrían desarrollar una triple función, no necesariamente excluyente. En primer lugar, como los centros de control de las élites locales sobre el territorio más próximo; en segundo lugar, como los espacios de negociación entre estas élites locales y las élites estatales, siguiendo la propuesta de S. Castellanos e I. Martín ${ }^{107}$; en último lugar, como entornos de articulación territorial del propio reino suevo en los territorios más periféricos y difíciles de controlar, en un momento en el que su entramado político se encontraría en construcción. Más dudas cabe tener, a falta de registros arqueológicos fiables, sobre los momentos de abandono de estos asentamientos fortificados y la relación que podría tener dicho abandono, eventualmente, con las dinámicas sociopolíticas derivadas de la consolidación del estado suevo a mediados del siglo vi d.n.e. o con la asimilación de este por parte del estado visigodo.

Estas disparidades cronológicas también serían visibles, al menos parcialmente, en los entornos rurales en abierto. Como comentamos antes, el proceso de emergencia y de consolidación de las granjas y aldeas parece mostrar similitudes con respecto a lo documentado en otros territorios del centro y norte peninsular. Por el momento, y ante la ausencia de más registros -fundamentalmente bioarqueológicos-, se puede también explicar por los mismos procesos de aumento de la autonomía y control de la producción de las sociedades campesinas altomedievales, que permitirían el desarrollo de estos espacios basados en la unidad doméstica y sin la presencia, aparentemente, de las élites rurales en los propios contextos aldeanos ${ }^{108}$. Por el contrario, lo que destaca en el noroeste peninsular es la continuidad y estabilidad del poblamiento rural altomedieval

105 SÁnchez PARdo, «Sobre las bases económicas».

106 Candelas Colodrón, César. O Cronicón de Hidacio. Bispo de Chaves. A Coruña: Toxosoutos, 2004.

107 Castellanos, Santiago y Martín Viso, Iñaki. «The local articulation of central power in the north of the iberian Peninsula (500-1000)». Early Medieval Europe, 2005, vol. 13, n.o 1, pp. 1-42.

108 Quirós Castillo, Juan Antonio y Vigil-Escalera Guirado, Alfonso. «Archaeology of medieval peasantry in northwestern Iberia». En Gelichi, Sauro y Olmo Enciso, Lauro (eds.). Mediterranean landscapes in post-Antiquity. New frontiers and new perspectives. Oxford: Archaeopress, 2019, pp. 129-144. 
una vez se ha constituido como tal. Los casos de As Pereiras y de A Pousada destacan precisamente por las largas cronologías que presentan, ambos entre los siglos VII/VIII y $\mathrm{x} / \mathrm{xI}$ d.n.e. La diferencia fundamental con los territorios del centro y norte peninsular estaría en que la octava centuria no supondría un momento de ruptura tan significativo para el poblamiento rural en llano ${ }^{109}$. De nuevo, como hipótesis, cabría plantear que los procesos políticos del «largo siglo viII» tuvieron un impacto relativo en la configuración del poblamiento rural, si bien, a tenor de lo que se comienza a conocer de los castillos, sí pudo tener más repercusión en la reconfiguración de las redes de poder de las élites del momento ${ }^{110}$, cuyos intereses estarían volcados, sobre todo, al control y articulación política y económica de estas aldeas y granjas.

El segundo elemento que particulariza el territorio del interior de la Gallaecia en este período es la presencia, muy temprana, de elementos vinculados a una élite territorial potente, al menos para lo conocido en la meseta norte durante este período. El caso del territorio de Valdeorras es particularmente interesante en este sentido. La documentación de un conjunto más que significativo de elementos ornamentales, muy posiblemente vinculados a diferentes edificios religiosos post-romanos, mostrarían no solo un territorio especialmente dinámico con un flujo importante de productos de lujo, sino la presencia de ciertos grupos con una cierta capacidad de atracción de capital social, económico y simbólico. Grupos que, además, podemos relacionar con élites religiosas, cuyo poder en este período debió de ser especialmente significativo, como se desprende de otros registros documentales y arqueológicos ${ }^{111}$. Esta preeminencia de las élites religiosas podría vincularse a la temprana alianza que establecieron estas con el Estado suevo, y que promocionaría su poder dentro de los territorios controlados por este Estado, primero, y, posteriormente, por el Estado visigodo ${ }^{112}$.

Por su parte, la presencia de un número nada despreciable de cecas, incluso en territorios aparentemente periféricos como el que se ha expuesto de Casaio, mostraría un interés por parte de las élites sociales por el control de estos espacios liminales. Se podría decir, a modo de hipótesis, que el interior de la Gallaecia durante el período a partir de la sexta centuria se convertiría en una periferia política -muy lejano a los intereses más inmediatos de las monarquías sueva y visigoda-, pero un potencial centro económico que promocionaría a una élite territorial particularmente poderosa. En cuanto a las bases económicas de estas élites, si bien la hipótesis de J. C. Sánchez Pardo sobre la importancia que tendrían actividades económicas como el comercio o la minería es muy sugerente y muy posiblemente sea una de las razones para la particularización que aquí estamos describiendo ${ }^{113}$, todos los datos expuestos anteriormente parecerían mostrar una élite, en términos generales, fundamentalmente agraria, cuya riqueza y agencia política

109 Tejerizo García, Arqueología de las sociedades campesinas.

110 Fernández Pereiro, Recintos fortificados; Fernández Pereiro, Mario. "O recinto fortificado do Monte Aloia. Un xigante altomedieval esquecido». Lucentum, 2019, vol. 38, pp. 379-395.

111 Sánchez Pardo, «Sobre las bases económicas»; SÁnchez Pardo, «Poblamiento rural tardorromano".

112 Díaz Martínez, El Reino Suevo.

113 SÁnchez Pardo, «Sobre las bases económicas». 
dependería del control ejercido sobre el conjunto de granjas y aldeas que, por primera vez, se reconocen de forma clara en el registro arqueológico.

\section{Conclusiones}

En este trabajo se han presentado algunos de los principales datos y las reflexiones surgidas a partir de un proyecto de investigación en marcha sobre las dinámicas y transformaciones del poblamiento rural en el interior del territorio de la antigua provincia de la Gallaecia entre el Tardoimperio y la Alta Edad Media. Partiendo de un enfoque comparativo y fundamentado en datos principalmente arqueológicos, uno de los objetivos principales era comprender las semejanzas y particularidades de este territorio, tradicionalmente entendido en términos de excepcionalidad. Así, se han reconocido arqueológicamente algunos fenómenos que representan una cierta novedad en la historiografía y el registro de este territorio, como es la relevancia de las granjas y aldeas en la configuración del paisaje altomedieval -si bien ya habían sido reconocidos con anterioridad, pero no insertados en un cuadro de análisis mayor-. Igualmente, otros fenómenos ya conocidos, como las reocupaciones de asentamientos fortificados, han sido detallados y contextualizados dentro de un marco histórico específico. Finalmente, se han podido resaltar las particularidades de este territorio, en contraste con otros entornos peninsulares mejor conocidos, que incluyen no solo unas particulares cronologías, sino también la presencia de grupos de poder específicos y diferenciados, que no hacen sino señalar la importancia de los marcos comparativos y territoriales en términos de escala -política y geográficapara entender este período en toda su complejidad.

No cabe duda de que muchas de estas afirmaciones, debido a la falta de registro empírico y de análisis más detallados, todavía deben quedar en el terreno de la hipótesis y de la sugerencia. Sin embargo, el reconocimiento de ciertos patrones de poblamiento rural y de ciertas dinámicas tanto semejantes como particulares con respecto a otros contextos peninsulares, abren un abanico muy estimulante de posibilidades para una futura agenda de trabajo. Una agenda de trabajo que pasa no solo por la generación de registros de mejor calidad, sino también por la combinación de las diversas fuentes disponibles para la interpretación de un período que, hasta hace muy poco, ha sido especialmente pantanoso para el análisis del noroeste peninsular ${ }^{114}$. En cualquier caso, tal vez la conclusión más importante sea que, poco a poco, se impone la necesidad, ya expuesta por autores como Ch. Wickham ${ }^{115}$, de tratar el período que va desde los momentos finales del Imperio Romano hasta la definitiva imposición de las dinámicas feudales no en términos de subalternidad, sino como un tiempo con unas esencias y problemáticas propias.

114 Ibid.

115 Wiскнам, The inheritance of Rome. 


\section{REFERENCIAS BIBLIOGRÁFICAS}

Aboal Fernández, Roberto y Cobas Fernández, Isabel. «La Arqueología en la Gasificación de Galicia 10: sondeos en el yacimiento romano-medieval de As Pereiras». TAPA, 1999, vol. 13.

Alcorta Irastorza, Enrique J. «Muralla romana de Lugo. Novedades en el trienio 2000-2003». En Morillo Cerdán, Ángel (ed.). Producción y abastecimiento en el ámbito militar. Arqueologia militar romana en Hispania II. León: Universidad de León, 2006, pp. 601-623.

Alcorta Irastorza, Enrique J. Lucus Augusti (vol. II): cerámica común de cocina y mesa hallada en las excavaciones de la ciudad. A Coruña: Fundación Pedro Barrié de la Maza, 2001.

Alcorta Irastorza, Enrique J. y Bartolomé Abraira, Roberto. "Muestras de cerámica engobada romana de producción local de Lucus Augusti (Lugo)». En Bernal Casasola, Darío y Ribera i Lacomba, Albert (eds.). Cerámicas hispanorromanas II. Producciones regionales. Cádiz: Universidad de Cádiz, 2012, pp. 699-724.

Arias VILAs, Felipe. «Apuntes sobre a ocupación do territorio na Galicia baixorromana: castros e vilas». En Galicia: da romanidade á xermanización. Problemas históricos e culturais. Actas do encontro cientifico en homenaxe a Fermin Bouza Brey (1901-1973). Santiago de Compostela: Museo do Pobo Galego, 1993, pp. 201-208.

Arias Vilas, Felipe. «Poblamiento rural: la fase tardía de la cultura castreña». En Fernández Осно, Carmen (ed.). Los finisterres atlánticos en la Antigüedad: época prerromana y romana. Gijón: Electa, 1996, pp. 181-188.

AriÑo Gil, Enrique. «Modelos de poblamiento rural en la provincia de Salamanca (Espańa) entre la antigüedad y la Alta Edad Media». Zephyrus, 2006, vol. 59, pp. 317-357.

Arizaga Castro, Álvaro R. y Ayán Vila, Xurxo M. «Etnoarqueología del paisaje castreño. La segunda vida de los castros». En González García, Francisco Javier (ed.). Los pueblos de la Galicia Céltica. Madrid: Akal, 2007, pp. 445-531.

Ayán Vila, Xurxo. Casa, familia y comunidad en la Edad del Hierro del NW. Santiago de Compostela: Xurimaru Servizos de Comunicación, 2012.

Blanco Rotea, Rebeca; Prieto Martínez, M. a Pilar; Ballesteros, Paula y López González, Luis F. "Capítulo 11. El despoblado de A Pousada: la formación de una aldea rural en la Alta Edad Media». En Prieto Martínez, M. a Pilar y Criado Boado, Felipe (eds.). Reconstruyendo la historia de la comarca del Ulla-Deza (Galicia, España). Escenarios arqueológicos del pasado. Santiago de Compostela: Consejo Superior de Investigaciones Científicas, 2009.

Blanco ToRrejón, Laura. «Entre lo pagano y lo cristiano. Espacios funerarios romanos y tardoantiguos en Galicia». Gallaecia, 2018, vol. 37, pp. 81-102.

Caballero Zoreda, Luis y Utrero Agudo, María de los Ángeles. Iglesias tardoantiguas y altomedievales en la Península Ibérica. Análisis arqueológico y sistemas de abovedamiento. Madrid: Consejo Superior de Investigaciones Científicas, 2006.

Candelas Colodrón, César. O Cronicón de Hidacio. Bispo de Chaves. A Coruña: Toxosoutos, 2004.

Carlsson-Brandt Fontán, Erik. «El poblamiento rural romano en Galicia. Resultados preliminares». Férvedes, 2011, vol. 7, pp. 207-213.

Castellanos, Santiago y Martín Viso, Iñaki. «The local articulation of central power in the north of the iberian Peninsula (500-1000)». Early Medieval Europe, 2005, vol. 13, n.o 1, pp. $1-42$.

Cepeda, Juan José. «Monedas procedentes del castro de Penadominga (Bendollo, Quiroga. Lugo)». Numisma, 1993, vol. 232, pp. 91-107. 
Costa García, José Manuel; Fonte, João y Gago, Manuel. «The reassessment of the Roman military presence in Galicia and northern Portugal through digital tools: archaeological diversity and historical problems». Mediterranean Archaeology and Archaeometry, 2019, vol. 19, n. ${ }^{\circ}$ 3, pp. 17-49.

Criado Boado, Felipe. Arqueología del paisaje. El área Bocelo-Furelos entre los tiempos paleolíticos y medievales. A Coruña: Xunta de Galicia, 1992.

Criado Boado, Felipe; Martínez López, María del Carmen y Amado Reino, Xesús. La arqueología en la gasificación de Galicia 1: programa de control y corrección de impacto arqueológico. Santiago de Compostela: Universidade de Santiago de Compostela, 1998.

Díaz Martínez, Pablo de la Cruz. «El alcance de la ocupación sueva de Gallaecia y el problema de la germanización». En Galicia: da romanidade á xermanización: problemas históricos e culturais: actas do encontro cientifico en homenaxe a Fermin Bouza Brey (19011973). Santiago de Compostela: Museo do Pobo Galego, 1993, pp. 209-226.

Díaz Martínez, Pablo de la Cruz. El Reino Suevo (411-585). Tres Cantos: Akal, 2011.

Durán Fuentes, María Consuelo. Moedas do Museo do Castro de Viladonga. Santiago de Compostela: Xunta de Galicia, 2009.

Enciclopedia del románico. Ourense (2 tomos). Aguilar de Campoo: Fundación Santa María la Real, 2015.

Escalona Monge, Julio. "The early Castilian peasantry: an archaeological turn?». Journal of Medieval Iberian Studies, 2009, vol. 1, n. ${ }^{\circ}$ 2, pp. 119-145.

Escalona Monge, Julio. "The Early Middle Ages: a scale-based approach». En Escalona MonGE, Julio y Reynolds, Andrew (eds.). Scale and scale change in the Early Middle Ages. Exploring landscape, local society, and the world beyond. Turnhout: Brepols, 2011, pp. 9-30.

Fernández Fernández, Adolfo. El comercio tardoantiguo (ss. IV-VII) en el Noroeste peninsular a través del registro cerámico de la ría de Vigo. Oxford: Archaeopress, 2014.

Fernández Fernández, Adolfo y Bartolomé Abraira, Roberto. "Cerámicas tardoantiguas en el noroeste de la Península (Galicia y norte de Portugal): entre la importación y el artesanado local/regional». En Quirós Castillo, Juan Antonio y Vigil-Escalera Guirado, Alfonso (eds.). La cerámica de la Alta Edad Media en el cuadrante noroeste de la Peninsula Ibérica (siglos $V-X)$. Sistemas de producción, mecanismos de distribución y patrones de consumo. Bilbao: Universidad del País Vasco, 2016, pp. 69-111.

Fernández Mier, Margarita. Génesis del territorio en la Edad Media: arqueología del paisaje y evolución histórica en la montaña asturiana. Oviedo: Universidad de Oviedo, 1999.

Fernández Mier, Margarita; Tejerizo García, Carlos y Aparicio Martínez, Patricia. «El territorio de Cea entre la tardo-romanidad y la Alta Edad Media». En Catalán Ramos, Raúl; Fuentes Melgar, Patricia y Sastre Blanco, José Carlos (eds.). Las fortificaciones en la tardoantigüedad. Élites y articulación del territorio (siglos V-VIII d. C). Madrid: La Ergástula, 2014, pp. 159-177.

Fernández Pereiro, Mario. «O recinto fortificado do Monte Aloia. Un xigante altomedieval esquecido». Lucentum, 2019, vol. 38, pp. 379-395.

Fernández Pereiro, Mario. Recintos fortificados en altura na costa atlátinca galega. Estudo arqueolóxico. Tesis inédita. Santiago de Compostela: Universidad de Santiago de Compostela, 2018.

Fernández Pereiro, Mario; Tejerizo García, Carlos; Rodríguez González, Celtia; Lixó Gómez, Carlos y Carvajal Castro, Álvaro. "Asentamentos fortificados no interior da Gallaecia en época tardoimperial e sueva (séc. IV-VI): un achegamento a partir de varios casos de estudo». Gallaecia, 2017, vol. 36, pp. 129-162. 
García de Cortázar, José Ángel. «La formación de la sociedad feudal en el cuadrante noroccidental de la Península Ibérica en los siglos 8 a 12». Initium: Revista Catalana d'Historia del Dret, 1999, vol. 4, pp. 57-121.

González Ruibal, Alfredo. Galaicos. Poder y comunidad en el Noroeste de la Península Ibérica (1200 a. C-50 d. C). A Coruña: Museo Arqueolóxico e Histórico de A Coruña, 2006-2007.

Lage Pillado, Manuel. Fíbulas galaico-romanas do Castro de Viladonga. Santiago de Compostela: Xunta de Galiza, 2004.

López Alsina, Fernando. «Da protoparroquia ou parroquia antiga altomedieval á parroquia clásica en Galicia». En García Pazos, Fernando (ed.). A parroquia en Galicia: pasado, presente e futuro. Santiago de Compostela: Xunta de Galiza, 2009, pp. 57-75.

López Costas, Olalla y Muldner, Gundula. "Fringes of the empire: diet and cultural change at the Roman to post-Roman transition in NW Iberia». American Journal of Physical Anthropology, 2016, vol. 161, pp. 141-154.

López Quiroga, Jorge. El final de la antigüedad en la Gallaecia: la transformación de las estructuras de poblamiento entre Miño y Duero (siglos V al X). La Coruña: Fundación Pedro Barrié de la Maza, 2004.

López Quiroga, Jorge y Lovelle, Mónica R. «Castros y castella tutiora de época sueva en Galicia y norte de Portugal: ensayo de inventario y primeras propuestas interpretativas». Hispania Antiqua, 1999, vol. XXIII, pp. 355-374.

Martín Viso, Iñaki. Asentamientos y paisajes rurales en el occidente medieval. Madrid: Editorial Síntesis, 2016.

Martín Viso, Ińaki. Poblamiento y estructuras sociales en el norte de la Península Ibérica (siglos VIXIII). Salamanca: Ediciones Universidad de Salamanca, 2000.

Martín Viso, Iñaki; Fuentes Melgar, Patricia; Sastre Blanco, José Carlos y Catalán Ramos, Raúl. Cerámicas altomedievales en Hispania y su entorno (s. V-VIII). Madrid: Glyphos, 2018.

Menéndez Llorente, Adriángela. «Aportaciones al estudio de la sigillata en la comarca de Valdeorras (Orense)». En Actas del XXII Congreso Nacional de Arqueología. Vigo: Artes Gráficas Galicia, 1995, pp. 309-312.

Morchón VIÑAs, Javier. Informe valorativo 1. Excavación arqueológica en área en el yacimiento de Casanova, GA27001016 Castromaior, S. Xoán de Castromaior (Abadín, Lugo). Informe inédito depositado en el Museo de Viladonga, 2008.

Morchón VIÑAs, Javier. Informe valorativo 2. Excavación arqueológica en área en el yacimiento de Casanova, GA27001016 Castromaior, S. Xoán de Castromaior (Abadin, Lugo). Informe inédito depositado en el Museo de Viladonga, 2009.

Nión Álvarez, Samuel. «Brigantium no século xxi: aproximación aos últimos datos arqueolóxicos da ocupación galaicorromana na cidade de A Coruña (s. I-IV d. C.)». Gallaecia, 2018, vol. 37, pp. 39-79.

Nissen-Jaubert, Anne. «Le haut Moyen Âge». En Ferdière, Alain; Malrain, François; Matterne, Véronique; Méniel, Patrice y Nissen-Jaubert, Anne (eds.). Histoire de l'agriculture en Gaule. Paris: Éditions Errance, 2006, pp. 141-197.

Pallares Méndez, María del Carmen y Portela Silva, Ermelindo. «La villa por dentro: testimonios galaicos de los siglos x y xI». Studia Historica. Historia Medieval, 1998, vol. 16, pp. $13-43$.

Parcero Oubiña, César. «Tres para dos. Las formas de poblamiento en la Edad del Hierro del Noroeste Ibérico». Trabajos de Prehistoria, 2000, vol. 57, n. ${ }^{\circ}$ 1, pp.75-95.

Pérez Losada, Fermín. Entre a cidade e a aldea. Estudio arqueo-histórico dos 'aglomerados secundarios'romanos en Galicia. A Coruña: Museo Arqueolóxico de A Coruña, 2002. 
Pliego Vázquez, Ruth. La moneda visigoda. (2 vols.). Sevilla: Universidad de Sevilla, 2009.

PORTASs, Robert. The village world of early medieval northern Spain. Local community and the land market. London: The Royal Historical Society, 2017.

Quirós Castillo, Juan Antonio. «Introducción». En Quirós Castillo, Juan Antonio y Tejado Sebastián, José María (eds.). Los castillos altomedievales en el noroeste de la Península Ibérica. Bilbao: Universidad del País Vasco, 2012, pp. 17-27.

Quirós Castillo, Juan Antonio. «Medieval Archaeology in Spain». En Gilchrist, Roberta y Reynolds, Andrew (eds.). 50 years of medieval archaeology in Britain and beyond. London: Routledge, 2009, pp. 173-189.

Quirós Castillo, Juan Antonio (ed.). Social complexity in Early Medieval Rural Communities. The north-western Iberia Archaeological Record. Oxford: Archaeopress, 2016.

Quirós Castillo, Juan Antonio y Vigil-Escalera Guirado, Alfonso. «Archaeology of medieval peasantry in northwestern Iberia». En Gelichi, Sauro y Olmo EnCIso, Lauro (eds.). Mediterranean landscapes in post-Antiquity. New frontiers and new perspectives. Oxford: Archaeopress, 2019, pp. 129-144.

Rodríguez Colmenero, Antonio. Galicia meridional. Bilbao: Universidad de Deusto, 1977.

Rodríguez Fernández, Tomás. «El fin del mundo fortificado y la aparición de las 'aldeas abiertas'. La evidencia del centro-oriente de Lugo (Samos y Sarria)». Espacio, Tiempo y Forma. Serie I, Prehistoria y Arqueología, 1994, vol. 7, pp. 153-189.

Rodríguez González, Xulio y Xusto Rodríguez, Manuel. Santomé. Conxunto arqueolóxico natural. Ourense: Xunta de Galicia, 2019.

Rodríguez Lovelle, Mónica y López Quiroga, José. «El poblamiento rural en torno a Lugo en la transición de la antigüedad al feudalismo (ss. v-x)». Cuadernos de Estudios Gallegos, 2000, vol. 47, n. $^{\circ} 113$, pp. 53-76.

Rodríguez SÁnchez, Brais. "O proceso de abandono dos castros. 'Continuidades' e 'rupturas' entre a Idade do Ferro e a Alta Idade Media. Un estado da cuestión». Gallaecia, 2012, vol. 31, pp. 139-151.

Sánchez-Palencia Ramos, Franscisco Javier (ed.). Las Médulas (León): un paisaje cultural en la "Asturia Augustana». León: Diputación de León, 2000.

SÁnchez Pardo, José Carlos. «Castros, castillos y otras fortificaciones en el paisaje sociopolítico de Galicia (siglos iv-Xi)». En Quirós Castillo, Juan Antonio y Tejado Sebastián, José María (eds.). Los castillos altomedievales en el noroeste de la Península Ibérica. Bilbao: Universidad del País Vasco, 2012, pp. 29-56.

SÁnchez PARdo, José Carlos. "Castros y aldeas galaicorromanas: sobre la evolución y transformación del poblamiento indígena en la Galicia romana». Zephyrus, 2010, vol. LXV, pp. 129-148.

Sánchez Pardo, José Carlos. "Crismón de Quiroga». En Villares, Ramón (ed.). 100 Galicia Cen. Obxectos para contar unha cultura. Santiago de Compostela: Consello da Cultura Galega, 2016, pp. 79-81.

SÁnchez Pardo, José Carlos. «Organización eclesiástica y social en la Galicia tardoantigua. Una perspectiva geográfico-arqueológica del parroquial suevo». Hispania Sacra, 2014, vol. 134, pp. 439-480.

Sánchez Pardo, José Carlos. "Poblamiento rural tardorromano y altomedieval en Galicia (ss. V-X). Una revisión arqueológica». Archeologia Medievale, 2010, vol. XXXVII, pp. 285-306.

SÁnchez Pardo, José Carlos. "Power and rural landscapes in early medieval Galicia (400-900 $\mathrm{AD})$ : towards a re-incorporation of the archaeology into the historical narrative». Early Medieval Europe, 2013, vol. 21, n. ${ }^{\circ}$ 2, pp. 140-168. 
Sánchez Pardo, José Carlos. "Power strategies in the early medieval churches of Galicia (711910 AD)». En Sánchez Pardo, José Carlos y Shapland, Michael G. (eds.). Churches and social power in Early Medieval Europe. Integrating Archaeological and Historical Approaches. Turnhout: Brepols, 2015, pp. 227-268.

Sánchez Pardo, José Carlos. «Sobre las bases económicas de las aristocracias en la Gallaecia suevo-visigoda (ca. 530-650 d. C.). Comercio, minería y articulación fiscal». Anuario de Estudios Medievales, 2014, vol. 44, n. ${ }^{\circ}$ 2, pp. 983-1023.

Sánchez Pardo, José Carlos y Galbán Malagón, Carlos J. «Fortificaciones de altura en el entorno de Santiago de Compostela. Hacia un primer análisis arqueológico comparativo». Nailos, 2014, vol. 2, pp. 125-161.

Sánchez Pardo, José Carlos; Blanco Rotea, Rebeca y Sanjurjo Sánchez, Jorge. «The church of Santa Comba de Bande and early medieval Iberian architecture: new chronological results». Antiquity, 2017, vol. 358, pp. 1011-1026.

Sastre Blanco, José Carlos; Fuentes Melgar, Patricia y Catalán Ramos, Raúl. Las fortificaciones en la tardoantigüedad. Élites y articulación del territorio (siglos V-VIII d. C.). Madrid: La Ergástula, 2014.

Sastre Prats, Inés. «Estructura de explotación social y organización del territorio en la civitas Zoelarum». Gerión, 1999, vol. 17, pp. 345-359.

Soto Arias, Purificación. «Estudio de un asentamiento romano ligado a la vía XVIII en el Valle de Valdeorras (Ourense)». Minius, 1993, vol. II-III, pp. 53-81.

Tejerizo García, Carlos. «Settlement patterns and social inequality: The Duero Basin in Early Middle Ages (4th-8th centuries)». En Quirós Castillo (ed.). Social complexity in Early Medieval Rural Communities. The north-western Iberia Archaeological Record. Oxford: Archaeopress, 2016, pp. 17-34.

Tejerizo García, Carlos. "The end of the world as we know it: post-imperial social lanscapes in North-Central Iberia (5th-6th centuries)». Archeologia Medievale, 2016, vol. XLIII, pp. 383-397.

Tejerizo García, Carlos. Arqueología de las sociedades campesinas en la cuenca del Duero durante la Primera Alta Edad Media. Bilbao: Universidad del País Vasco, 2017.

Tejerizo García, Carlos y Canosa Betés, Jorge. «Power, control and social agency in post-roman northern Iberia: an archaeological analysis of hillfort occupations». Journal of Medieval Iberian Studies, 2018, vol. 10, n. ${ }^{\circ}$ 3, pp. 295-323.

Tejerizo García, Carlos y Quirós Castillo, Juan Antonio. «Treinta años de arqueología en el norte de la Península Ibérica. La 'otra' Arqueología Medieval». En Quirós Castillo, Juan Antonio (ed.). Treinta años de Arqueología Medieval en España. Oxford: Archaeopress, 2018, pp. 123-146.

Tejerizo García, Carlos y Vigil-Escalera Guirado, Alfonso. «Castro Ventosa y La Cabeza de Navasangil: una revisión de sus secuencias de ocupación y del fenómeno de los asentamientos fortificados altomedievales». Nailos, 2017, vol. 4, pp. 129-161.

Tejerizo García, Carlos; Alonso Toucido, Francisco y Torres Iglesias, Diego. «Propuesta de secuenciación cerámica en contextos rurales del interior de Galicia desde el Tardoimperio a la Alta Edad Media (ss. v-x/xi d.n.e.)». En prensa.

Tejerizo García, Carlos; Rodríguez González, Celtia y Fernández Pereiro, Mario. «¿Continuidad o discontinuidad en los castros del noroeste? Una revisión del yacimiento de Viladonga (Castro de Rei, Lugo)». SPAL, 2019, vol. 28, n. ${ }^{\circ}$ 2, pp. 279-313. 
Tejerizo García, Carlos; Rodríguez González, Celtia y Fernández Pereiro, Mario. «Materiais cerámicos tardíos (ss. IV-vi d. C.) no castro de Viladonga». CROA. Boletín da Asociación de Amigos do Museo do Castro de Viladonga, 2018, vol. 28, pp. 36-52.

Tejerizo García, Carlos; Carvajal Castro, Álvaro; Marín Suárez, Carlos; Martínez Álvarez, Cristina y Mansilla Hortigǘla, Rafael. «La construcción histórica de los paisajes en el sector central de la cuenca del Duero. Primeros resultados de una prospección intensiva». Territorio, Sociedad y Poder, 2015, vol. 10, pp. 39-62.

Tereso, Sofia; Brito, André; Umbelino, Cláudia; Cipriano, Miguel; André, Clara y Carvalho, Pedro C. «Arqueologia funerária alto medieval da Torre Velha (Castro de Avelas, Bragança)». En Quirós Castillo, Juan Antonio y Castellanos, Santiago (eds.). Identidad y etnicidad en Hispania. Propuestas teóricas y cultura material en los siglos V-VIII. Bilbao: Universidad del País Vasco, 2015, pp. 146-160.

Torres, Casimiro. Galicia sueva. A Coruña: Fundación Pedro Barrié de la Maza, 1977.

Tranoy, Alain. La Galice Romaine. Recherches sur le nord-ouest de la Péninsule Ibérique dans l'Antiquité. Paris: Publications du Centre Pierre Paris, 1981.

Veiga Romero, Ana M. a. "Los mosaicos de A Cigarrosa. Historia de un hallazgo». Museo Arqueolóxico Provincial de Ourense, 2009.

Vigil-Escalera Guirado, Alfonso. «Granjas y aldeas altomedievales al norte de Toledo (450-800 d. C)». Archivo Español de Arqueología, 2007, vol. 80, pp. 239-284.

Vigil-Escalera Guirado, Alfonso. "Los últimos 30 años de la arqueología de época visigoda y altomedieval». En Quirós Castillo (ed.). Treinta años de Arqueología Medieval en España. Oxford: Archaeopress, 2018, pp. 271-294.

Vigil-Escalera Guirado, Alfonso y Quirós Castillo, Juan Antonio. La cerámica de la Alta Edad Media en el cuadrante noroeste de la Península Ibérica (siglos V-X). Bilbao: Universidad del País Vasco, 2016.

Vigo García, Abel. Intervención arqueolóxica en Os Castros (Mondoñedo, Lugo). Memoria técnica inédita, 2017.

Wiскнам, Chris. «Problemas de comparación de sociedades rurales en la Europa occidental de la temprana Edad Media». Anales de Historia Antigua y Medieval, 1996, vol. 29, pp. 45-70.

Wiскнам, Chris. Framing the Early Middle Ages. Oxford: Oxford University Press, 2005.

Wicknam, Chris. The inheritance of Rome: A History of Europe from 400 to 1000. London: Penguin, 2009. 